OPEN ACCESS

Edited by:

Margarita Sáiz,

Severo Ochoa Molecular Biology

Center (CSIC-UAM), Spain

Reviewed by:

Yukun Qin

Institute of Oceanology (CAS), China

Renukaradhya J. Gourapura,

The Ohio State University,

United States

*Correspondence:

Michael R. Hamblin

Hamblin.lab@gmail.com

Maryam Ghandali

ghandali.maryam@gmail.com

Hamed Mirzaei

mirzaei-h@kaums.ac.ir;

h.mirzaei2002@gmail.com

${ }^{+}$These authors have contributed equally to this work

Specialty section: This article was submitted to Virus and Host,

a section of the journal

Frontiers in Cellular

and Infection Microbiology

Received: 07 January 2021

Accepted: 22 February 2021

Published: 17 March 2021

Citation:

Boroumand H, Badie F, Mazaheri S, Seyedi ZS, Nahand JS, Nejati M,

Baghi HB, Abbasi-Kolli M,

Badehnoosh B, Ghandali M,

Hamblin MR and Mirzaei H (2021)

Chitosan-Based Nanoparticles

Against Viral Infections.

Front. Cell. Infect. Microbiol. 11:643953.

doi: 10.3389/fcimb.2021.643953

\section{Chitosan-Based Nanoparticles Against Viral Infections}

\author{
Homa Boroumand ${ }^{1 \dagger}$, Fereshteh Badie ${ }^{2 \dagger}$, Samaneh Mazaheri ${ }^{3}$, Zeynab Sadat Seyedi ${ }^{4}$, \\ Javid Sadri Nahand ${ }^{5}$, Majid Nejati ${ }^{6}$, Hossein Bannazadeh Baghi ${ }^{7,8}$, Mohammad Abbasi-Kolli ${ }^{9}$, \\ Bita Badehnoosh ${ }^{10}$, Maryam Ghandali ${ }^{11 *}$, Michael R. Hamblin ${ }^{12^{*}}$ and Hamed Mirzaei ${ }^{13^{*}}$ \\ 1 School of Medicine, Kashan University of Medical Sciences, Kashan, Iran, ${ }^{2}$ Department of Microbiology, Faculty of \\ Medicine, Kashan University of Medical Sciences, Kashan, Iran, ${ }^{3}$ Department of Analytical Chemistry, Faculty of Chemistry, \\ University of Kashan, Kashan, Iran, ${ }^{4}$ Department of Cell and Molecular Biology, Faculty of Chemistry, University of Kashan, \\ Kashan, Iran, ${ }^{5}$ Department of Virology, Faculty of Medicine, Iran University of Medical Sciences, Tehran, Iran, ${ }^{6}$ Anatomical \\ Sciences Research Center, Institute for Basic Sciences, Kashan University of Medical Sciences, Kashan, Iran, ${ }^{7}$ Department \\ of Microbiology, Faculty of Medicine, Tabriz University of Medical Sciences, Tabriz, Iran, ${ }^{8}$ Infectious and Tropical Diseases \\ Research Center, Tabriz University of Medical Sciences, Tabriz, Iran, ${ }^{9}$ Department of Medical Genetics, Faculty of Medical \\ Sciences, Tarbiat Modares University, Tehran, Iran, ${ }^{10}$ Department of Gynecology and Obstetrics, Dietary Supplements and \\ Probiotic Research Center, Alborz University of Medical Sciences, Karaj, Iran, ${ }^{11}$ School of Medicine, Iran University of \\ Medical Sciences, Tehran, Iran, ${ }^{12}$ Laser Research Centre, Faculty of Health Science, University of Johannesburg, \\ Doornfontein, South Africa, ${ }^{13}$ Research Center for Biochemistry and Nutrition in Metabolic Diseases, Institute for Basic \\ Sciences, Kashan University of Medical Sciences, Kashan, Iran
}

Viral infections, in addition to damaging host cells, can compromise the host immune system, leading to frequent relapse or long-term persistence. Viruses have the capacity to destroy the host cell while liberating their own RNA or DNA in order to replicate within additional host cells. The viral life cycle makes it challenging to develop anti-viral drugs. Nanotechnology-based approaches have been suggested to deal effectively with viral diseases, and overcome some limitations of anti-viral drugs. Nanotechnology has enabled scientists to overcome the challenges of solubility and toxicity of anti-viral drugs, and can enhance their selectivity towards viruses and virally infected cells, while preserving healthy host cells. Chitosan is a naturally occurring polymer that has been used to construct nanoparticles (NPs), which are biocompatible, biodegradable, less toxic, easy to prepare, and can function as effective drug delivery systems (DDSs). Furthermore, chitosan is Generally Recognized as Safe (GRAS) by the US Food and Drug Administration (U.S. FDA). Chitosan NPs have been used in drug delivery by the oral, ocular, pulmonary, nasal, mucosal, buccal, or vaginal routes. They have also been studied for gene delivery, vaccine delivery, and advanced cancer therapy. Multiple lines of evidence suggest that chitosan NPs could be used as new therapeutic tools against viral infections. In this review we summarize reports concerning the therapeutic potential of chitosan NPs against various viral infections.

Keywords: viral infection, chitosan, nanoparticles, delivery system, therapy 


\section{INTRODUCTION}

Infectious diseases caused by bacteria, fungi, viruses, and parasites are responsible for nearly 15 million deaths globally, of which human immunodeficiency virus (HIV), malaria, tuberculosis, as well as acute respiratory infection including the newly emerged COVID-19 have been considered to be the key causes of death (Panácek et al., 2009; Li et al., 2011; Qasim et al., 2014). Viral infections cause substantial health concerns that affect millions of individuals globally, and negatively impact human health and socio-economic development (Mehendale et al., 2013; Nahand et al., 2020a; Nahand et al., 2020b). Effective treatments of viral infections are limited by increased incidence of drug resistance, particularly related to HIV (Little et al., 2002; Shafer et al., 2007; Lockhat et al., 2016; Maseko et al., 2016) and influenza (Hayden, 2009). Drug resistant viral infections are a public health threat, causing widespread morbidity as well as mortality (Cosgrove, 2006), and additional costs caused by expensive drugs (Li et al., 2011; Qasim et al., 2014). Therefore, there is an urgent need to develop novel approaches to prevent and treat these viral infections.

Nanotechnology is concerned with particles with sizes within the nanometer range from $10^{-9}$ or 1 billionth of a meter (Nalwa, 1999; Parboosing et al., 2012). Nanobiotechnology refers to interactions of nanoscience with biological systems (Scheller et al., 1995; Niemeyer, 2006). Nanomedicine involves the use of nano-structured materials for the diagnosis, prevention, or treatment of diseases (Medepalli, 2008). The first use of nanoparticles (NPs) in medicine was to increase the solubility and stability of drugs with low bioavailability (Schütz et al., 2013). NPs can exert antiviral activity through several mechanisms. Firstly, NPs are useful in viral treatment due to their specific features, such as small particle size (Kumar et al., 2012; Parboosing et al., 2012), high ratio of surface area to volume (McNeil, 2011), and adjustable surface charge (Caron et al., 2010; Petros and DeSimone, 2010). Secondly, it has been shown that NPs can display biomimicry features (Bowman et al., 2008; Sanvicens and Marco, 2008; Gagliardi, 2017), and therefore can exert intrinsic antiviral activity; e.g. silver nanoparticles (AgNPs) (Sun et al., 2005; Lara et al., 2010) or dendrimers (Wang et al., 2006; Mallipeddi and Rohan, 2010). Thirdly, NPs can also increase the stability of the loaded drug, allowing dose optimization and more predictable delivery, which all stem from the drug encapsulation ability (Chiappetta et al., 2011; Kumar et al., 2012). NPs can be tailored to create stable structures (Goldberg et al., 2007), or modified by attachment of polyethylene glycol (PEG) (Gabizon et al., 1994; Alexis et al., 2008; McNeil, 2011; Santos-Martinez et al., 2014). Fourthly, engineered NPs can significantly enhance drug delivery by the use of targeting moieties that recognize receptors or biomarkers to increase the specificity for target cells, target tissues, or subcellular compartments (Muthu and Singh, 2009; Petros and DeSimone, 2010; McNeil, 2011).

Chitosan $(\mathrm{CH})$ is a modified biopolymer obtained via partial de-acetylation of the naturally occurring polysaccharide called chitin, which contains randomly distributed $(1 \rightarrow 4)$-linked Nacetyl glucosamine and glucosamine units (Rashki et al., 2021). $\mathrm{CH}$ can be obtained as a white powder, composed of rigid, inflexible, and nitrogen-containing polysaccharide chains of varying length and molecular weight (Badawy and Rabea, 2011). In addition, $\mathrm{CH}$ has multi-faceted applications because of its non-toxicity, bio-degradability, and intrinsic antimicrobial properties. $\mathrm{CH}$ has been used in biomedical preparations, genetic engineering, agricultural sector, environmental pollution control, food manufacturing, paper manufacturing, photography, and water treatment (Cheba, 2011). CHNPs show interesting interface and surface effects due to their very small size (Ingle et al., 2008). Several studies have suggested that CH NPs could be used as new therapeutic options against viral infections.

\section{CHITOSAN (CH) AND CH NPS}

$\mathrm{CH}$ is a straight chain, cationic polysaccharide that is prepared by partial deacetylation of chitin, which is commonly carried out by alkaline hydrolysis (Figure 1). $\mathrm{CH}$ commonly refers to cationic co-polymers that contain 2 amino 2 -deoxy- $\beta$ - $\mathrm{D}$-glucose residues ( $60 \%$ to $100 \%)$ as well as 2 acetamino-2-deoxy- $\beta$-D-glucoside residues $(0 \%$ to $50 \%)$, attached together by $\beta(1 \rightarrow 4)$ bonds (Nasrollahzadeh et al., 2020; Tao et al., 2020). The mean degree of deacetylation is usually $>60 \%$ ( $\mathrm{Ng}$ et al., 2002; Varma et al., 2004). The average degree of deacetylation and the molecular weight specifies the total number of amide residues and the number of primary amine residues, and this ratio directly influences the $\mathrm{CH}$ solubility and the chemical, biological and physical properties (Kmiec et al., 2017; Jaworska et al., 2020; Rashki et al., 2020; Yang et al., 2020a).

The $\mathrm{CH}$ amino groups are more reactive compared to the acetamido-groups of chitin. In fact, the nitrogen free-electron pair in the amino groups can bind to metallic cations, and the average degree of deacetylation determines their number. In addition, protonation of the amino groups in an acidic solution will electrostatically attract surrounding anions (Kmiec et al., 2017).

$\mathrm{CH}$, unlike chitin, can be dissolved in a dilute acidic solution to form a soluble cationic polymer, which has different properties to other polysaccharides (Kmiec et al., 2017). Following a lengthy period of agitation, $\mathrm{CH}$ can be dissolved in dilute acids like acetic, formic, lactic, or inorganic acids. Nonetheless, the solubility depends on the degree of deacetylation, molecular weight, bio-polymer concentration, pH, and ionic strength (Varma et al., 2004). In addition to the primary amino groups, $\mathrm{CH}$ contains numerous primary and secondary hydroxyl-groups at the C-2, C-3 and C-6 positions, which show robust interactions with water (Peter, 1995).

$\mathrm{CH}$ has advantages such as biodegradability, hydrophilicity, biocompatibility, bioactivity, and is obtained from renewable and natural sources. It can be processed into distinct forms, such as solutions, blends, sponges, membrane, gels, paste, tablets, microspheres, or microgranules for different applications (Kumar et al., 2004; Pillai et al., 2009).

Henri Braconnot first discovered chitin in 1811 while researching different mushrooms. Next, Prof. C. Rouget (1859) found that alkaline treatment of chitin produced a material, which could be dissolved in acids, unlike chitin. Hoppe Seiler was the first to call this deacetylated chitin "chitosan" (Badawy and Rabea, 2011). Next to cellulose, chitin is the most widespread 


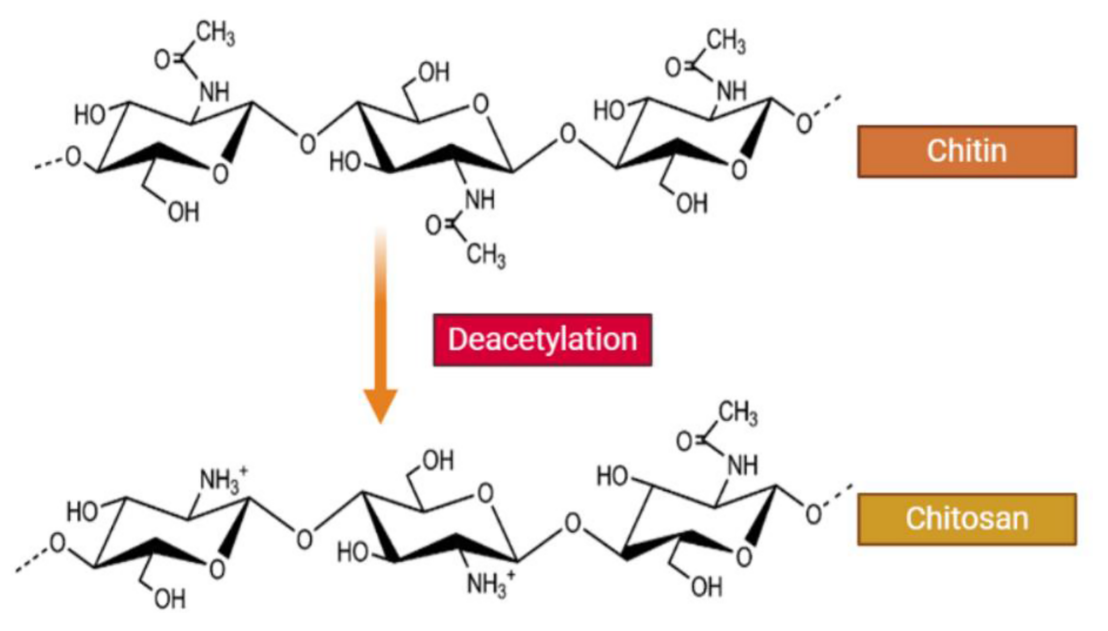

FIGURE 1 | Structure of chitin and chitosan. $\mathrm{CH}$ is a naturally occurring water-soluble cationic polysaccharide that is generated by alkaline deacetylation of chitin. $\mathrm{CH}$ is a linear polysaccharide composed of $\beta$-(1-4) linked 2-acetamide-2-deoxy-D-glucose (a neutral sugar unit GlcNAc or A-unit) and 2-amino 2-deoxy-D-glucose (a cationic sugar unit GlcN or D-unit). $\mathrm{CH}$ can have a broad range of degree of deactylation $\left(\mathrm{F}_{\mathrm{A}}\right)$, as well as variable chain length and molecular weight.

biopolymer found in all of the natural world. Chitin is the main component of insect cuticles, yeast, green algae and fungal cell walls (Einbu and Varrum, 2008), and is also found in crab and shrimp shells (Wang and Xing, 2007). On the other hand, chitosan itself is very rare in nature, being only found in the cell walls of certain fungi (Muzzarelli et al., 1986; Yen et al., 2009). There are three principal types of chitin called $\alpha, \beta$, and $\gamma$. The $\alpha$-chitin possesses anti-parallel chains, whereas $\beta$-chitin possesses parallel chains formed by in-sheet hydrogen bonds. The $\gamma$-chitin is made up from combinations of $\alpha$ and $\beta$ chitin types with both parallel and anti-parallel chain arrangements (Franca et al., 2008; Yen et al., 2009).

\section{PREPARATION OF CH NPS}

The most common procedures for preparing $\mathrm{CH}$-based NPs are, emulsion based solvent evaporation, ionotropic gelation, solvent diffusion, emulsification, as well as the microemulsion method (Garg et al., 2019; Zhang et al., 2019; Ansari et al., 2020). Some of the benefits associated with the above techniques include the use of less organic solvent and the need for a lower force. However, the size and surface charge of the $\mathrm{CH}$ NPs prepared via the above procedures, depend on the degree of deacetylation and the molecular weight (Mohammed et al., 2017). In addition, hydrophobic interactions, electrostatic interactions, and hydrogen bonding all govern the extent to which drugs will be entrapped inside the polymeric matrix. Moreover, the drug loading and drug release will need to be investigated for each application of CH NPs, considering the physiological environment at the administration site. In fact, both the ionic strength and the presence of enzymes or proteins will affect drug release and stability (e.g., the milieu of the eye versus the GI tract). It is fortunate that there are numerous techniques available to prepare the optimum $\mathrm{CH}$ NP formulation for each application (Mohammed et al., 2017).

\section{Ionotropic Gelation}

Calvo et al. were the first to describe the ionotropic gelation method for the preparation of $\mathrm{CH}$ NPs. Thereafter, additional experts in the field investigated and developed it further (Calvo et al., 1997). This procedure relies on electrostatic interactions between the amine groups of $\mathrm{CH}$ and a variety of polyanions with a negative charge, such as tri-polyphosphate (Divya and Jisha, 2018). First it is necessary to dissolve the $\mathrm{CH}$ in acetic acid in the presence or the absence of a stabilizing agent, such as a poloxamer. In the next step, the polyanion is added, and the NPs are spontaneously generated by mechanical shaking at room temperature. It is possible to modify the size as well as the surface charge of the particles by varying the $\mathrm{CH}$-to-stabilizer molar ratio (Divya and Jisha, 2018). Researchers have found an overall increase in the particle compactness and size by increasing the $\mathrm{CH}$ concentration and the ratio of polymer-to-polyanion (Jonassen et al., 2012). Results indicated that NPs dispersed in a saline solution showed higher stability and a smaller particle size in the presence of sodium chloride, which may be caused by the monovalent sodium salt screening out the electrostatic repulsion between the positively charged amine groups on the $\mathrm{CH}$ backbone. The presence of salt may enhance the flexibility within the polymer chain as well as its stability (Ilium, 1998).

\section{Polyelectrolyte Complexes (PEC)}

A polyelectrolyte complex is formed when plasmid DNA is mixed with a cationic charged polymer such as $\mathrm{CH}$, which selfassembles into nanostructures because the anionic charge on the DNA is neutralized by the cationic polymer (Divya and Jisha, 2018). Spontaneous formation of CH NPs occurs after adding the DNA solution to the $\mathrm{CH}$ dissolved in acetic acid solution with mechanical shaking at room temperature (Erbacher et al., 1998).

\section{Reverse Micelles Preparation}

Brunel et al. first described a method for the preparation of reverse micelles (Brunel et al., 2008). A key benefit was the 
absence of poisonous organic solvents and cross-linkers. Moreover, it was possible to obtain ultra-fine NPs in a narrow size range by this technique (Divya and Jisha, 2018). The $\mathrm{CH}$ aqueous solution is poured into an organic solvent containing a surfactant with constant agitation to allow the formation of reverse micelles (Zhao et al., 2011).

\section{Microemulsion Method}

In the microemulsion procedure, $\mathrm{CH}$ is mixed with glutaraldehyde in an acetic acid solution and poured into a surfactant in an organic solvent such as hexane (Mohammed et al., 2017). Then the mixture is continuously shaken at room temperature overnight. This covalent cross-linking reaction results in the formation of $\mathrm{CH}$ NPs. In the next step, the organic solvent is removed via evaporation under vacuum (Mohammed et al., 2017). Excessive surfactant can be removed via precipitation with calcium chloride and centrifugation. The resultant NP suspension is finally dialyzed and lyophilized (Maitra et al., 1999). The CH NPs show a very narrow size distribution, which can be controlled by varying the glutaraldehyde concentration (Wang et al., 2008). The disadvantages of the microemulsion method are the need for an organic solvent, a prolonged reaction time, and a complicated washing-step (Nagpal et al., 2010).

\section{Emulsification and Solvent Diffusion}

In order to prepare an oil-in-water emulsion, an aqueous solution of $\mathrm{CH}$ and a stabilizer is mixed with an organic solvent by mechanical shaking accompanied by increased pressure homogenization (Niwa et al., 1993; El-Shabouri, 2002). Precipitation is caused by adding a large amount of water into the emulsion, and the NPs are formed with a size ranging between $300 \mathrm{~nm}$ and $500 \mathrm{~nm}$. This procedure is a good choice to load hydrophobic molecules, with a high entrapment efficiency (EE\%); however, a key caveat is the need for an increased shear force (Mohammed et al., 2017).

\section{CHITOSAN AS AN ADJUVANT FOR ANTIVIRAL VACCINES}

As the second most plentiful polysaccharide in nature, $\mathrm{CH}$ has seen widespread utilization in drug formulation and pharmaceutics, due to its non-toxicity, biodegradability, biocompatibility, and its ability to cross tight epithelial junctions (Ilium, 1998). CH can open tight intercellular junctions, thus allowing the loaded drugs to penetrate better into tissue and be taken up by target cells (Van Der Lubben et al., 2001a; Van der Lubben et al., 2001b; Van der Lubben et al., 2001c). CH NPs are also promising biomaterials to improve antigen delivery and the performance of vaccines. The association of antigens with chitosan-based nanoparticle systems, has shown that antigen uptake by mucosal lymphatic tissues is increased, resulting in more potent mucosal and systemic immune responses to different antigens (Bramwell and Perrie, 2006). Chitosan has mucoadhesive properties, which increases the long-term adhesion of the CH NPs, and therefore a longer time in contact with the bloodstream capillaries, leading to greater uptake of the antigen protein or the plasmid DNA (Khatri et al., 2008a).

The respiratory mucosal surface acts as a primary immune defense barrier, and is the main site of influenza virus infection. Many studies have shown that mucosal vaccines could be used to induce both a systemic and a local mucosal immune response (Yuki and Kiyono, 2003). When vaccines are combined with an adjuvant, the induction of mucosal immunity is improved. Some adjuvants are toxins, such as Escherichia coli heat-labile toxin or cholera toxin (Glück et al., 2000). However these toxins can cause acute diarrhea and damage to the central nervous system (CNS) (van Ginkel et al., 2000). Therefore, the development of more effective and safer adjuvants is essential to improve mucosal immunization.

Recently, the use of self-assembled biodegradable CH NPs has emerged as an efficient vaccine delivery system (Uto et al., 2007). The interaction of NPs with antigens leads to improved antigenspecific acquired immune responses by increasing the uptake by antigen presenting cells, such as dendritic cells (DCs) and macrophages (Figure 2) (Akagi et al., 2005).

In addition, when NPs are taken up by DCs, it leads to upregulation of costimulatory molecules, stimulation of cytokine production, and increased T-cell stimulation (Uto et al., 2007). Therefore, NP delivery systems have been proposed as efficient adjuvants for sub-unit vaccines. Nevertheless, the nonbiodegradable nature of many types of NPs is a problem with the delivery of vaccines. Moreover, poly-gamma-glutamic acid (g-PGA), which is a capsular polymer secreted by Bacillus subtilis, is considered to be a safer alternative. (Poo et al., 2010). Moon et al. (2012) described a type of hybrid NPs composed of g-PGA plus $\mathrm{CH}$. They showed that the hybrid NPs allowed intranasal immunization by an inactivated virus or by the model antigen, recombinant influenza hemagglutinin protein (rHA) leading to increased anti-HA immunoglobulin A (IgA) and IgG responses. This intranasal vaccination protocol protected mice against infection with a pathogenic dose of influenza type A H5N1 virus (Moon et al., 2012).

Mucosal immunization can lead to a mucosal immune response with or without a systemic immune response. The mucosal response was due to the production of secreted $\operatorname{IgA}(\operatorname{sg} A)$ antibody, without the production of systemic immunization (Nugent, 1998). However, it is accepted that oral vaccination shows higher efficiency. Degradation of antigens in the acidic stomach environment as well as enzymatic degradation in the intestinal tract contributes to the higher efficacy of oral vaccination (Gabor et al., 2002; Lavelle et al., 2004; Singh et al., 2004).

Chowdhury et al. described the production of a mucosal influenza vaccine system, which showed broad cross-protection against both emerging and seasonal influenza A viruses. They loaded poly- $\gamma$-glutamic acid ( $\gamma$-PGA)-chitosan NPs (PC NPs) with the strongly conserved matrix protein-2 (sM2), the mucosal adjuvant cholera toxin subunit A1 (CTA1), and a fusion peptide of hemagglutinin $\left(\mathrm{HA}_{2}\right)$, all of which have been demonstrated to be safe natural substances with the ability of being absorbed by mucosal membrane as a mucosal adjuvant (Chowdhury et al., 2017). Results of the study showed that mucosal administration of this sM2HA2CTA1/PC NP preparation could trigger both local 


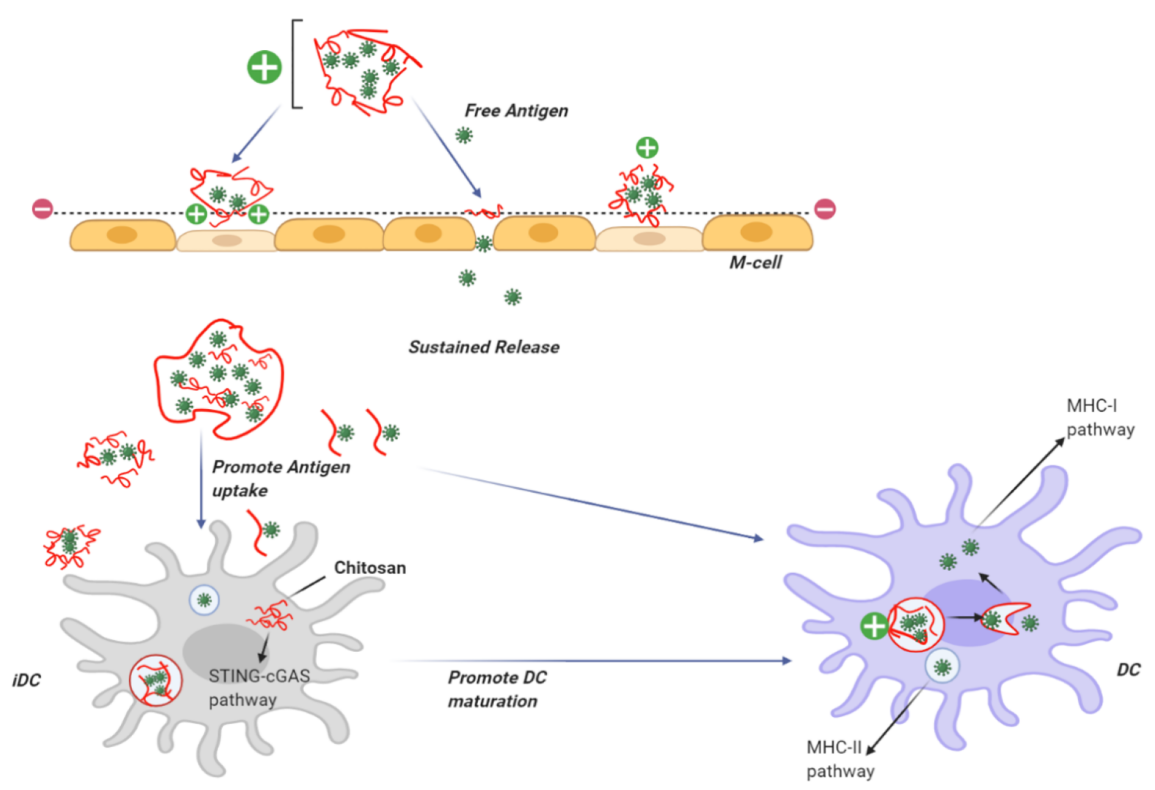

FIGURE 2 | Use of chitosan as an adjuvant for vaccine delivery. CH can be dissolved in acid to provide a positive charge on the particle surface. CH NPs containing antigens can adhere to the cell surface in the nasal mucosa giving a prolonged residence time. $\mathrm{CH}$ can open the tight junctions and allow the transfer of free antigens through the para-cellular route, as well as the transcytosis of the packaged antigens via $\mathrm{M}$-cells. $\mathrm{CH}$ becomes insoluble at physiological pH, providing slow release of encapsulated antigens and uptake bydendritic cells DCs. Following uptake by DCs, CH activates the STING-cGAS pathway resulting in DC maturation. After the insoluble particles have been taken up by cells via endocytosis, $\mathrm{CH}$ becomes soluble at the acidic $\mathrm{pH}$ and the antigens escape from the lysosomes into the cytoplasm for cross presentation through the MHC-I pathway. Antigens taken up by DCs can berouted to the MHC-II pathway.

immunity (IgA\& IgG) at the inoculation site, and remote systemic immunity. In addition, researchers confirmed that the inclusion of sM2 and HA2 triggered specific cell-mediated immune responses. The following challenge tests were carried out in BALB/c mice. IAV strains: A/Puerto Rico/8/34(H1N1), $10 \mathrm{MLD}_{50}$ of $\mathrm{A} / \mathrm{EM} /$ Korea/W149/06(H5N1), A/Aquatic bird/Korea/W44/2005 (H7N3), A/Chicken/Korea/116/2004(H9N2), and A/Aquatic bird/Korea/W81/2005(H5N2). The sM2HA2CTA1/PC NPs showed protection against several lethal influenza sub-types, and the protection remained for up to 6 months following the vaccination. Therefore, sM2HA2CTA1/PC NPs may be an attractive option for a global influenza vaccine (Chowdhury et al., 2017).

Another study investigated the intranasal administration of NPs consisting of $\mathrm{CH}$ and poly- $\gamma$-glutamic acid ( $\gamma$-PGA), and loaded with rHA antigen or an inactivated virus, for the induction of a high-degree of protective mucosal immunity in the respiratory tract (Moon et al., 2012). These researchers found that intranasal immunization with $\gamma$-PGA/CHNPs (PC NPs), containing either inactivated virus or $\mathrm{rHA}$ antigen, resulted in a good $\mathrm{IgG}$ response in the serum and an IgA response in the lung, with anti-HA neutralizing antibodies and influenza virus-specific cell-mediated immune responses. Therefore, PC NPs were capable of functioning as a potent mucosal adjuvant in comparison to cholera toxin (CT), which is a frequently used mucosal adjuvant. The mice were protected against challenge with a lethal dose of pathogenic influenza A H5N1 virus after intranasal administration of PC NPs loaded with rHA antigen, or the inactivated virus. It could be possible to combine PC NPs with a recombinant sub-unit influenza antigen manufactured on a large scale by a prokaryotic expression system (Moon et al., 2012).

However, low uptake of antigens by the gut-associated lymphoid tissue (GALT) leads to decreased effectiveness. Therefore a large dosage of antigen may be needed for effective immunity (Gupta et al., 2006). Mishra and colleagues (Mishra et al., 2014) tested hybrid NPs composed of $\mathrm{CH}$ plus Lotus tetragonolobus lectin (LTA) for mucosal immunization against the hepatitis B virus (HBV). In this study, the mucosal immunity was evaluated by examining salivary, intestinal, and vaginal secretions of IgA. LTA-conjugated $\mathrm{CH}-\mathrm{NPs}$ evoked robust humoral and cellular responses, and could be used for oral mucosal immunization against HBV (Mishra et al., 2014).

In another study, Zhao et al. (2017) investigated NPs prepared from N-2-hydroxy-propyl trimethyl ammonium chloride modified $\mathrm{CH}$ (N-2-HACC) as well as N,Ocarboxymethyl-modified $\mathrm{CH}$ (CMC) as carriers and adjuvants for vaccination. The modified $\mathrm{CH}$ NPs showed a higher stability and lower cytotoxicity than unmodified $\mathrm{CH}$ NPs. Both vehicles allowed steady release of antigens, following an early burst release. Moreover, in another study, N-2-HACC-CMC/NDV NPs administered intranasally, produced higher titers of IgA and IgG antibodies, and higher proliferation of lymphocytes, as well as increased levels of IL-2, IL-4 and IFN- $\gamma$. N-2-HACC$\mathrm{CMC}$ may be a suitable delivery carrier and adjuvant for mucosal vaccines, as well as for transmucosal drug delivery (Zhao et al., 2017). 


\section{THE EFFECT OF CH AND ITS DERIVATIVES ON VIRAL INFECTIONS}

$\mathrm{CH}$ is widely used in both human and veterinary medicine (Muzzarelli et al., 1998), therefore, its pharmacological properties, and especially its effect on the immune system have been studied in detail. Chitosan strongly modulates the functional activity of many immune cells, such as granulocytes and macrophages. After subcutaneous implantation, $\mathrm{CH}$ triggered chemotaxis of Canis familiaris L. macrophages, and increased nitric oxide production by macrophages in vitro. It also stimulated leukocytosis in the peripheral blood of laboratory dogs. The secretion of nitric oxide was mainly due to the $\mathrm{N}$-acetylglucosamine residues in chitosan, which was more effective than $\mathrm{N}$-acetylmannosamine or $\mathrm{N}$ acetylgalactosamine (Chirkov, 2002).

The function of macrophages is critical for an effective immune system response. Macrophages are antigen-presenting cells, and their interaction with T-helper cells stimulates cellular and humoral immune responses. Stimulation of macrophage functional activity with $\mathrm{CH}$ can also be important for suppressing viral infection in animals. In this regard, it should be mentioned that when mouse alveolar macrophages took up chitosan or chitin NPs by phagocytosis, the generation of reactive oxygen species was increased. Likewise, mouse splenocytes secreted higher amounts of $\gamma$-interferon. Interferon is known to suppress virus replication by impairing the translation ability of genomic RNAs or early viral mRNAs (Shibata et al., 1997; Chirkov, 2002). Thus, the ability of $\mathrm{CH}$ to stimulate interferon synthesis by macrophages could be an additional antiviral mechanism. Chitosan inhibited the reproduction of Chlamydia trachomatis (an obligate intracellular parasite) within HeLa cells, mainly by suppressing the uptake of parasites by neighboring cells (Pawar et al., 2008). Chitosan enhanced antiviral immune responses by increasing the production of $\operatorname{IgG}$ and $\operatorname{IgA}$ antibodies against influenza A (Texas H1N1) and influenza B (Panama) viruses (Chirkov, 2002).

Sulfated chitosan derivatives have been synthesized to specifically inhibit retrovirus replication. Studies have shown that $\mathrm{N}$-carboxymethyl chitosan- $\mathrm{N}, \mathrm{O}$-sulfate could inhibit the synthesis of virus-specific proteins, and decrease HIV-1 replication in cultured T-cells, as well as the replication of Rausher murine leukemia virus in cultured mouse fibroblasts. It was found that sulfated $\mathrm{N}$-carboxymethyl chitosan prevented the interaction of the viral glycoprotein gp120 (the key viral coat protein) with its receptors on T-lymphocytes. This activity lessened the entry of the virus into CD4+ cells. In addition, the modified $\mathrm{CH}$ competitively inhibited the activity of virus specific reverse transcriptase, most probably through interference with the enzyme binding to its polyA-oligo-dT template. The chitosan derivative showed virtually no cytotoxicity towards these cell cultures (Chirkov, 2002; Kim, 2013). The highest activity was found with a chitosan derivative sulfated at the $\mathrm{O} 2$ and/or $\mathrm{O} 3$ positions within the glucosamine residues. This derivative was effective in inhibiting the replication of HIV-1 in MT-4 lymphocytes. The anionic polymer probably bound to the positively charged V3-loop in the gp120 molecule via an electrostatic interaction, preventing the fusion of the virus and the cell membrane (Chirkov, 2002). It was noted that, although the ability of anionic chitosan derivatives to inhibit retroviral infection was overall similar to the effects of sulfated polysaccharides, such as heparin, dextran sulfate, etc., the effectiveness and specificity depended on the position of the sulfate groups in the glucosamine residue.

Amino groups (NH2) and hydroxyl groups $(\mathrm{OH})$ are functional groups that mediate the biological activity of $\mathrm{CH}$ (Chen and Zhao, 2012). The molecular weight and degree of deacetylation of $\mathrm{CH}$ also play an important role in defining the biological activity (Tong and Chen, 2013). The number of amino groups affects the antibacterial and antioxidant activity (Klaykruayat et al., 2010; Xiao et al., 2011). Je and Kim (Je and Kim, 2006) found that aminoethyl modified chitosan provided an antioxidant effect against hydroxyl and superoxide anion radicals. Moreover, the antibacterial effects of aminoethylmodified chitosan were seen in the inhibition of Escherichia coli (Meng et al., 2012). Chitosan also showed antiviral effects against viral infections in plants and phage infections in bacteria (Pospieszny et al., 1991; Chirkov, 2002; Kulikov et al., 2006). One study suggested that aminoethyl-modified $\mathrm{CH}$ exerted its antiviral activity by stimulation of the immune response ( $\mathrm{He}$ et al., 2019).

Topical microbicides have been developed to prevent infection by human papillomaviruses (HPV). The main goal of these microbicides is to block the interaction between HPV virions and heparan sulfate proteoglycan (HSPG) molecules that act as receptors on the surface of the host cells (ShaftiKeramat et al., 2003). Heparin, as well as some heparin-like polysaccharides including dextran sulfate and carrageenan, have shown the ability to prevent HPV binding to the cell surface (Lembo et al., 2008). Various types of $\mathrm{CH}$ have also demonstrated this property (Wang et al., 2012). Sulfated CH shows a range of biological activities, including antitumor, antioxidant, anticoagulant and antiviral properties (Kulikov et al., 2006; Artan et al., 2010; Yang et al., 2013). Sulfated chito-oligosaccharide exerts an inhibitory effect on viral entry, as well as preventing virus-cell fusion through the inhibition of HIV-1gp120 binding to the CD4+ cell surface receptor. (Wang et al., 2012). Therefore, $\mathrm{CH}$ and its sulfated derivatives could be useful as new antiviral agents (Wang et al., 2012). To further investigate the antiviral properties of sulfated chitosans, a study by Gao et al. (2018) investigated the anti-HPV effects of 3,6-Osulfated $\mathrm{CH}$ (36S). They suggested that the anti-HPV effect of 3,6-O-sulfated $\mathrm{CH}$ could be due to targeting the viral capsid protein, and also to regulation of the host PI3K/Akt/mTOR pathways (Gao et al., 2018).

Recently, it has been reported that the wide use of current antiinfluenza drugs has led to the emergence of drug-resistant viruses (De Jong et al., 2005; Yen et al., 2013). Therefore, it is very important to discover new treatment approaches. Zheng and colleagues (Zheng et al., 2016) showed that the innate immune system could be stimulated by nasal administration of chitosan, and this was effective enough to protect $\mathrm{BALB} / \mathrm{c}$ mice from infection with the H7N9 virus, which is also highly pathogenic to humans 
(Zheng et al., 2016). Su et al. (2009) reported that high-molecularweight chitosan at high concentrations resulted in the inactivation of murine norovirus MNV-1. Li et al. synthesized a sialyl lactose$\mathrm{CH}$ derivative by grafting a lactoside aldehyde-functionalized aglycone onto the $\mathrm{CH}$ amino groups, followed by enzymatic sialylation using sialyl-transferase. The glycosylated $\mathrm{CH}$ bound the influenza virus surface hemagglutinin protein with high affinity to suppress virus binding to host cells (Figure 3) (Li et al., 2011)

\section{CHITOSAN VEHICLES FOR ANTIVIRAL DRUG DELIVERY}

Drug delivery systems (DDS) are used for controlled and sustained drug release as well as targeted delivery to specific cells and tissues (Figure 4). The primary advantage of these controlled-release systems is to lessen the side effects of drugs by widening the therapeutic range between the lowest effective and toxic concentrations. This approach can enhance patient satisfaction by decreasing the number of injections, reducing the overall dose, and increasing the specificity for the diseased site. Nonetheless, DDS still suffer from some limitations, like poor biocompatibility as well as possible toxicity of the matrix itself, or its bio-degradation products. The administration route may be problematic, for example surgical operation may be needed for implantation, and their cost may be high in comparison with conventional formulations (BernkopSchnürch and Dünnhaupt, 2012; Hu et al., 2013).

$\mathrm{CH}$ has biological properties such as being hemostatic, bacteriostatic, anti-cholesteremic, anti-carcinogenic, as well as fungistatic (Saikia et al., 2015), These activities have made it a popular candidate in biomedical applications like DDS. Since $\mathrm{CH}$ is a naturally occurring biopolymer, its biocompatibility and lack of toxicity are viewed as advantages. $\mathrm{CH}$ has been approved by the FDA as a hemostatic dressing called HemCon ${ }^{\mathrm{TM}}$ for battlefield and civilian medical uses (Wedmore et al., 2006). Both low and high molecular weight $\mathrm{CH}$ will undergo metabolism as well as enzymatic degradation within the body, leading to removal by renal clearance (Funkhouser and Aronson, 2007). Notably, the degradation rate is dependent on the degree of deacetylation. $\mathrm{CH}$ can be dissolved in acid, but then becomes insoluble at physiologic (7.4) or basic $\mathrm{pH}$. The presence of two hydroxyl groups on each structural unitas well as the primary amine groups, allows easy chemical modification, and facile physical interaction with metallic or metal oxide NPs, organic or inorganic compounds, and polymers (Luo and Wang, 2014; Abd Elgadir et al., 2015; Saikia et al., 2015). CH is preferred in the formulation of DDSs, because of its cationic nature allowing interaction with anionic drugs or compounds, its mucoadhesive properties, greater permeation into tissue, ability to allow cellular transfection of nucleic acids, and its suppression of multi-drug efflux pumps (Ngo et al., 2015).

Acquired immune deficiency syndrome (AIDS) is caused by infection with the HIV virus, and has caused the deaths of millions of people worldwide (das Neves et al., 2010; Sadri Nahand et al., 2020). A new therapeutic approach using a combination drug regimen, is called highly active antiretroviral therapy (HAART) (das Neves et al., 2010). Five different types of antiretroviral drugs have been used to treat AIDS (Wong et al., 2010), each of which functions at different stages of the viral lifecycle (Gupta and Jain, 2010). For example, a protease inhibitor targets the viral protease that cleaves the GAG-POL precursor responsible for producing the viral enzymes that are required for viral proliferation (Tritch et al., 1991). Currently, the FDA has approved eight protease inhibitors, of which saquinavir has shown the highest activity.

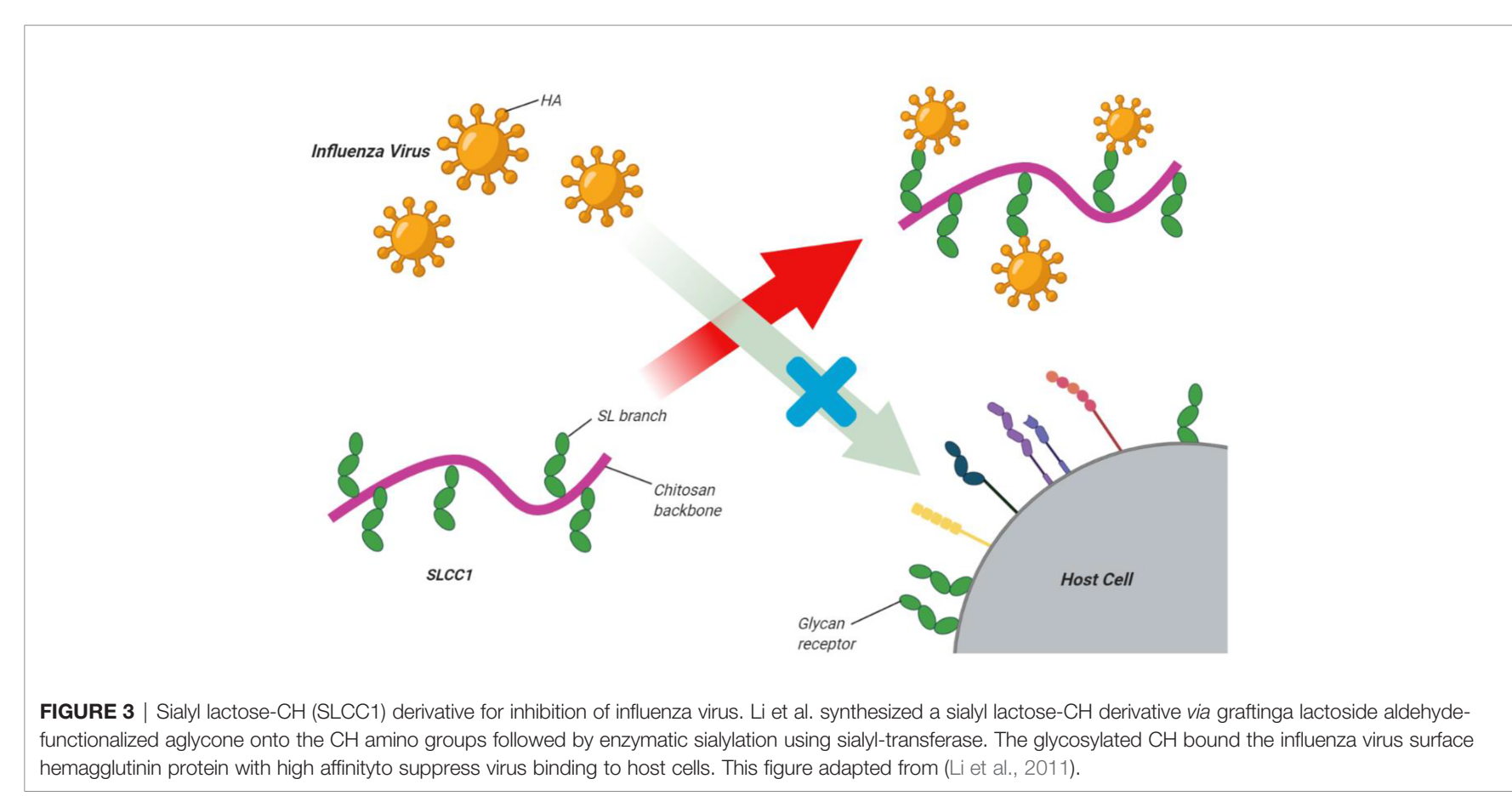




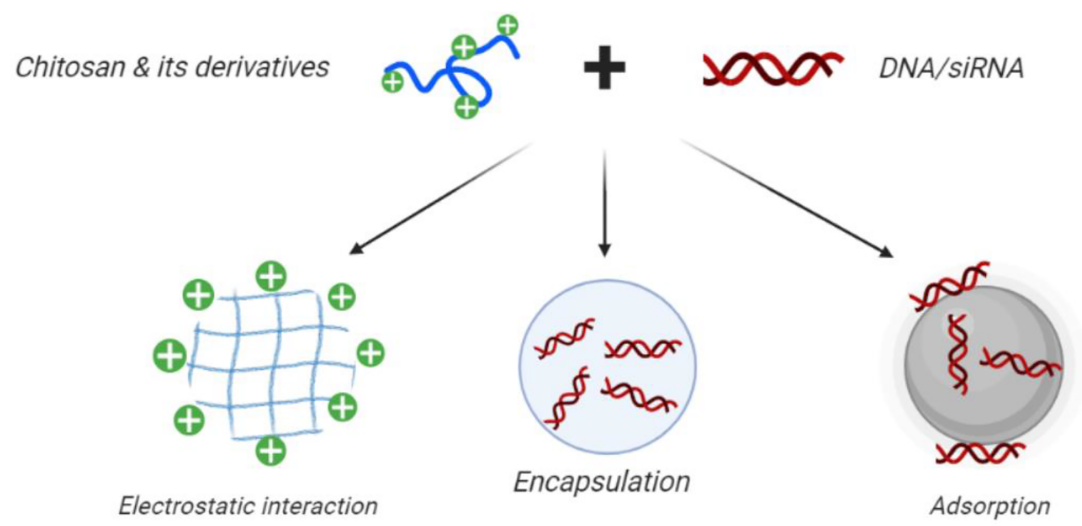

FIGURE 4 | Use of $\mathrm{CH}$ in gene therapy and gene silencing. Chitosan nanoparticles can be loaded with plasmid DNA, antisense oligonucleotides, or small interfering RNAs for targeted gene silencing. Positively charged $\mathrm{CH}$ can readily form polyelectrolyte complexes with negatively charged nucleic acids. This figure adapted from (Santos-Carballal et al., 2018).

Nevertheless, saquinavir has been shown to be limited by its poor bioavailability (Li and Chan, 1999), that has been largely ascribed to a group of MDR1 (multidrug resistance 1) drug efflux pumps. P-gp mediates anti-HIV drug efflux because of their similarity to the natural substrates of P-gp mediated efflux systems (Kim A. E. et al., 1998; Kim R. B. et al., 1998). Rapid efflux of the drugs causes a lower intracellular concentration of the drug within the cells. Another mechanism ssuggested for the lower bioavailability of saquinavir is its metabolism in the liver and small intestine, that results in rapid clearance (Thummel et al., 1997). The poor bioavailability of saquinavir necessitates the use of higher doses that could encourage the emergence of drug resistance (Schapiro et al., 1996). The use of saquinavir can have many side effects like nausea, dizziness, arrhythmia, etc. Hence, nanotechnology-based delivery vehicles could be used to increase the potency of saquinavir. Ramana et al. (2014) investigated a chitosan-based nanodelivery strategy for saquinavir. In this study, the $\mathrm{CH}$ NPs were loaded with saquinavir and characterized by transmission electron microscopy (TEM) and differential scan calorimetry. They also measured the encapsulation efficacy, swelling properties, zeta potential, and dimensions of the NPs. The cellular uptake of CHNPs was assessed by confocal microscopy and flow cytometry. The anti-viral effectiveness was studied in cell culture. The researchers reported a $75 \%$ efficiency for saquinavir encapsulation, and a cell targeting efficiency $>92 \%$. Saquinavir loaded $\mathrm{CH}$ carriers resulted in better control of viral proliferation compared to soluble drug alone, with two different HIV strains (NL4-3 and Indie-C1) and two different types of Tcells (CEM-CCR5 and Jurkat). This study demonstrated that better drug loading combined with increased cell targeting efficiency led to effective control of viral replication in the targeted T-cells (Ramana et al., 2014).

Herpes simplex virus type 1 (HSV-1) is an endemic highly transmissible virus, which is mainly transmitted by mouth-tomouth contact. It is projected to infect up to 3.7 billion people under 50 years old (D'Affronte and Platia, 2020). In fact, HSV-1 primary infection usually occurs in childhood as an asymptomatic infection, but can develop into herpetic gingivastomatitis with recurrent bouts of oral labial lesions (e.g., fever blisters, cold sores, or herpes labialis). HSV-2, which is primarily transmitted through sexual contact, causes genital herpes which affected about 417,000,000 people globally in 2012 (Roizman, 2006; D'Affronte and Platia, 2020). Different anti-herpes drugs like famciclovir, valacyclovir or acyclovir have been approved, and are used for treating acute symptomatic herpetic infections (Andrews et al., 2006; Le Cleach et al., 2014). Moreover, recurrent orolabial mucocutaneous herpes will usually be treated with topical anti-viral agents to accelerate wound healing and reduce symptoms like pain, tingling, itching, and burning (Spruance and Kriesel, 2002). In addition, acyclovir (9[(2-hydroxyethyl)methyl])-9H-guanine) is the treatment of choice for HSV infection. However, it should be administered several times a day to be effective, because of its short half-life as well as imperfect adsorption. Although acyclovir is used as a topical treatment (Zovirax), due to its hydrophilic nature and its poor solubility in both aqueous and fatty solvents, it does not penetrate well into the stratum corneum. New topical formulations of acyclovir have been designed to penetrate through the epidermis to reach the basal layer where the virus exists, at sufficient concentrations to inhibit replication (Prabhu et al., 2012). Donalisio and colleagues (Donalisio et al., 2018) investigated the effects of acyclovir-loaded $\mathrm{CH}$ nanospheres prepared by nanoemulsion templating for topical treatment of herpes-virus infections. The novel $\mathrm{CH}$ nanospheres were characterized by dynamic light scattering (DLS), TEM, and invitro drug release studies. A Franz cell was used to study the drug penetration through porcine skin ex vivo. Viral inhibition studies were done on Vero cells infected with HSV-2 and HSV-1 strains. The chitosan NS-loaded with acyclovir had a spherical shape about $200 \mathrm{~nm}$ in diameter and a $40.0 \mathrm{mV}$ negative zeta-potential. The drug loading capacity was nearly $8.5 \%$ and $30 \%$ of the acyclovir was released from the nanospheres within 6 h. Ex vivo skin penetration was better than with acyclovir $5 \%$ cream. The acyclovir-NS complex exhibited more potent anti-viral activity 
compared to free acyclovir against HSV-1 as well as HSV-2 strains. Furthermore, the acyclovir-loaded NS did not display any anti-proliferative activity or any sign of cytotoxicity against host cells (Donalisio et al., 2018).

In another study, Calderón et al. (2013) prepared microparticles (MPs) as well as NPs composed of CH crosslinked with tripolyphosphate to deliver acyclovir. The system showed biocompatibility, bioadhesive properties, and potential as a penetration enhancer through the skin. The amounts of acyclovir diffused within 24 hours were as follows: 30,40 , and $80 \mu \mathrm{g}$ for ACV alone, ACV + MP solution, and ACV loaded NPs respectively. Moreover, $\mathrm{CH}$-based particles caused less tissue damage and only moderate irritation as judged by the slug mucosal irritation (SMI) assay, suggesting that ACV-NPs could be used to develop an anti-viral formulation.

In another study, Hasanovic et al. (2009) created a skin delivery system for aciclovir based on $\mathrm{CH}$-tripolyphosphate NPs with good chemical stability. In this study, NPs were spontaneously formed by ionotropic gelation with tripolyphosphate. Two distinct dimensions of aciclovir-loaded NPs were characterized for their zeta-potential, particle size, and polydispersity index. A standard diffusion test with the use of a Franz diffusion-cell indicated good skin permeability dependent on the size of $\mathrm{CH}$ NPs, and good acyclovir loading. If the chitosan content of the NPs was higher, more acyclovir penetrated through porcine skin. Differential scanning calorimetry showed a significant reduction in the average transition temperature, showing that the NPs interacted with two layers (skin and fat). In addition, the chemical stability of acyclovir was considerably enhanced by NPs incorporation. After five weeks of photo-oxidation, the acyclovir content in the nanoparticles was remarkably higher than with a pure aqueous solution. The present study demonstrated that the incorporation of aciclovir within the $\mathrm{CH}$-tripolyphosphate NPs substantially enhanced the chemical stability. Skin diffusion was better with acyclovir CHNPs, particularly those with a high $\mathrm{CH}$ content (Hasanovic et al., 2009).

Applications of $\mathrm{CH}$ for drug delivery have been limited due to its low tissue penetration as well as its poor solubility at $\mathrm{pH}>5.6$. N,N, $\mathrm{N}$-trimethyl $\mathrm{CH}$ was prepared via amine functionalization, and showed improved chemical stability, solubility, biological adsorption, porosity, and non-antigenic properties (Hagenaars et al., 2009a). Therefore N-TMC has been proposed as a DDS for vaccines (Figure 4), drugs, biomolecules, antimicrobials, and as a scaffold matrix for skin, bone and nerve regeneration (Balmayor et al., 2012; de Britto et al., 2012; Radhakumary et al., 2011; Tsai et al., 2011).

In another study, Dehghan and colleagues (2014) investigated chitosan nanospheres to deliver an influenza vaccine. In this study, whole influenza virus combined either with CpG oligodeoxynucleotide (CpG ODN) or with Quillaja saponin (QS) as adjuvants, and incorporated into $\mathrm{CH}$ nanospheres. Three doses of the dry powder nanosphere vaccine were administered nasally into rabbits on days 0,45 , and 60 , with an additional booster dose on day 75. The cellular and humoral immune responses were examined, showing an increased titer of hemagglutination inhibition (HI) antibody in both groups in comparison with controls. $\mathrm{CH}$ nanospheres $(\mathrm{WV}+\mathrm{CpG})$ and $\mathrm{CH}(\mathrm{WV}+\mathrm{QS})$ were more effective that virus alone, and $\mathrm{CpG}$ alone $(\mathrm{p}<0.001)$. The $\mathrm{CH}(\mathrm{WV}+\mathrm{CpG})$ group showed the maximum response with rabbit serum IgG titer. The $\mathrm{CH}(\mathrm{WV}+\mathrm{CpG})$ resulted in higher induction of sIgA titers compared to $\mathrm{CH}(\mathrm{WV}+\mathrm{QS})(\mathrm{p}<0.001)$, and the $\mathrm{CpG}$ adjuvant had a major contribution to the secretion and stimulation of IL-2 and IFN-g cytokines (3-fold \& 3.5-fold increase). The $\mathrm{CH}(\mathrm{WV}+\mathrm{CpG})$ vaccine induced the best cellular and humoral immune responses against the influenza virus following nasal administration (Dehghan et al., 2014).

$\mathrm{CH}$ and its derivatives have been used for organ-specific targeted drug delivery. For instance some systems can target the liver by relying on passive accumulation of DDS by the reticulo-endothelial system (RES), or else by active targeting of the liver by recognition of the ligand-modified DDS by specific hepatic receptors. One study reported the synthesis of lactosaminated $\mathrm{N}$-succinyl- $\mathrm{CH}$, and investigated its potential as a liver-specific drug carrier (Kato et al., 2001). This carrier bound to the asialoglycoprotein receptor (ASGP-R) and accumulated in the liver. The lactose-conjugated $\mathrm{CH}$ modified with PEG formed polyionic complex micelles to deliver the anti-inflammatory drug called diammonium glycyrrhizinate to treat acute HBV infection (Yang et al., 2009). Another study from Lin et al. (2008) described the modification of CHNPs by conjugation to glycyrrhizin. Conjugation was achieved by the oxidation of glycyrrhizin using sodium periodate to form aldehyde groups, that could then react with $\mathrm{CH}$ amino groups (Lin et al., 2008). In-vitro investigations showed the localization of the glycyrrhizin conjugated CH NPs in hepatocytes, with an uptake 4.9 times greater than that of non-hepatic parenchymal cells. The dose of NPs and the incubation time governed the cellular uptake, that was mediated by ligand-receptor interactions (Singh et al., 2018).

Another group used a double emulsification procedure to prepare cationic PLGA-CH NPs with HBsAg passively absorbed onto the surface, for site-specific delivery of IFN- $\alpha$ to hepatocytes. The HbsAg-coated (99m)Tc labeled PLGA-CHNPs showed remarkable recovery of liver function compared with unmodified PLGA NPs (Giri et al., 2011). The size of the NPs as well the hydrophobicity affected the cell-mediated and mucosal immune responses. The HBsAg-modified NPs could be administered via pulmonary delivery. Hydrophobic particles $>$ $500 \mathrm{~nm}$ gave the best improvement in secreted IgA, IFN- $\gamma$, and interleukin-2 levels compared to hydrophilic particles $<500 \mathrm{~nm}$. Larger hydrophobic particles were taken up into rat alveolar macrophages to increase the immune response (Thomas et al., 2011). Polymeric NPs formulated for HBV gene silencing using the biodegradable polymer PLGA were more effective when the cationic polymer $\mathrm{CH}$ was incorporated into the matrix. The plasmid DNA loading efficiency and the cellular internalization were improved. In this regard, Zeng et al. (2011) showed improved HBV silencing with CH-PLGA system, than the plain plasmid DNA (pDNA) or simple PLGA NPs. The CH-PLGA system did not show any adverse effects (Zeng et al., 2011). Table 1 lists various chitosan nanoparticles that have been used as drug delivery systems for viral infections. 


\section{CHITOSAN VEHICLES FOR ANTIVIRAL VACCINATION}

Influenza occurs in pigs (swine flu) caused by the influenza Avirus (IAV) of the Orthomyxoviridae family. Influenza is an economically significant disease in the pig farming industry (Dykhuis-Haden et al., 2012; Crisci et al., 2013). Swine IAV (SwIAV) infection causes an acute febrile respiratory illness, which is frequently followed by secondary bacterial infections (Dykhuis-Haden et al., 2012). Moreover, the SwIAV virus modifies its genetic diversity via repeated antigenic drifts or shifts. The main circulating strains of SwIAV in pigs are H1N1, H1N2, and H3N2 (Vincent et al., 2008). Since pig respiratory tract epithelial cells have receptors for human IAVs as well as avian IAVs, pigs may become infected with IAV strains from various hosts. SwIAV infections allow genetic recombination as well as adaptation of new influenza strains that may infect humans and animals, and even cause epidemics (Ito et al., 1998). Commercially available swine flu vaccines are based on multivalent whole inactivated virus (WIV) vaccines given intramuscularly (IM). (Vincent et al., 2017). These WIV vaccines protect against homologous virus infection, however they cannot induce sufficient heterologous immunity against the continually evolving IAVs caused by point mutations (Van Reeth and Ma, 2012; Vincent et al., 2017).

In addition, when the IM pathway is utilized for WIV vaccines, it will not produce an effective mucosal immune response, that is really necessary to provide cross-protective immunity against different types of IAV (Tamura and Kurata, 2004; van Riet et al., 2012). An intranasal (IN) vaccine, which targets the respiratory tract mucosal immune system, could be an improvement over IM influenza vaccines employed in pigs. Additionally, nasal mucosal vaccination results in the induction of a powerful protective immune response in the respiratory tract, and also improves immunity at the distal mucosal and systemic sites (Neutra and Kozlowski, 2006; Kim and Jang, 2017). Various kinds of NPs have been studied for IN delivery of antigens in influenza vaccines. For instance, IN immunization in a mouse model using liposome-based DNA and influenza nanovaccines induced cellular, mucosal and humoral immune responses (Wang et al., 2004). Furthermore, poly (lactic-co-glycolic) acid (PLGA) NPs loaded with highlyconserved H1N1 influenza virus peptides and administered IN triggered epitope-specific T-cell responses, as well as protective immunity in pigs (Hiremath et al., 2016). A ferritin-based IN influenza nanovaccine increased mucosal IgA secretion, T-cell responses and provided homo-subtype and hetero-subtype protection in mice (Qi et al., 2018).

Hepatitis virus B (HBV) is a severe chronic infectious liver disease that can cause cirrhosis, hepatocellular carcinoma, and even mortality if left untreated. It is estimated there are 4.7 million clinical cases of acute HBV annually (Beisel et al., 2020). Considering that effective drug treatments for HBV are lacking, parenteral vaccines involving recombinant DNA encoding HBsAg are used to protect nearly 95\% of the recipients (Kwon and Lee, 2011). However the need for injection is expensive and causes patient dissatisfaction. Thus, a different administration route like intranasal (i.n.) using an appropriate DDS may be an alternative (Illum, 2003). The nasal mucosa has plentiful nasalassociated lymphoid tissue (NALT), a larger surface area, the presence of dendritic cells, as well as less enzymatic degradation compared to the oral route (Kang et al., 2009; Slütter et al., 2010). Finally, nasally administered drugs may have higher concentration, no first-pass effects, better permeation, and more patient compliance, without any side effects (Al-Qadi et al., 2011; Taranejoo et al., 2011).

Antigens encapsulated inside NPs and administered intranasally showed a higher uptake, a more controlled release of the antigens that can pass through the nasal membranes to reach the vasculature with higher immunogenicity and a systemic immune response (Kyd et al., 2001; Costantino et al., 2007). Moreover, DDS greater than $100 \mathrm{~nm}$ in size administered intranasally have a long residence time and mucoadhesive properties according to their surface charge, preventing polymer bio-degradation (Slütter et al., 2010).

Hepatitis-B virus surface antigen (HBsAg) was loaded into N, $\mathrm{N}, \mathrm{N}$-trimethyl chitosan NPs (N-TMC NPs) for controlled intranasal delivery as reported by Subbiah et al. (2012). The NP size was tunable by modifying the N-TMC content, giving $66 \pm 13$ $\mathrm{nm}$ for $0.25 \mathrm{wt} \%$, and $76 \pm 9 \mathrm{~nm}$ for $0.5 \mathrm{wt} . \%$. A HBsAg loading of 380 and $760 \mu \mathrm{L} / \mathrm{mL}$ resulted in $143 \pm 33,259 \pm 47 \mathrm{~nm}$-sized spherical N-TMC NPs with a loading efficiency of HBsAgantigen of $90 \%-93 \%$ and $96 \%-97 \%$ respectively. In-vivo immunological studies were conducted on 6-8 week old female BALB mice over 43 days, showing the high stability and efficiency of this HBV vaccination (Subbiah et al., 2012).

Recent approaches to treat hepatitis B have attempted to clear active HBV infections by suppressing viral replication. Some nucleoside or nucleotide analogs have been used as anti-viral drugs, to efficiently suppress HBV replication. In addition, lamivudine (LA) targets the host cell nucleus and inhibits the reverse transcriptase enzyme in order to terminate $\mathrm{HBV}$ replication (Asselah et al., 2005). There are some limitations of anti-viral drugs, such as non-specific biodistribution in-vivo, enzymatic metabolism, and issues in transportation across biological membranes (Langer, 1998). These limitations reduce the therapeutic benefit, require larger doses, and lead to side effects well as drug resistance. Moreover, by utilizing pharmaceutical engineering, the delivery of anti-viral drugs to their molecular targets will increase efficiency and decrease adverse effects. Earlier investigations revealed that the molecular activity of anti-HBV drugs largely takes place in subcellular organelles of the host cells, in addition to inhibiting HBV binding to its receptors (Zoulim and Perrillo, 2008). Thus, nanotechnology-based vehicles that can target sub-cellular organelles are an example of molecular targeted therapy (Torchilin, 2008). One example is stearic acid-grafted $\mathrm{CH}$ oligosaccharide polymeric micelles, that could target specific sub-cellular organelles (You et al., 2007; You et al., 2008).

Hydrophobic drugs are loaded into the hydrophobic core of the micelles via hydrophobic interactions, and possibly by metalligand coordination bonds (Nishiyama et al., 2001) or 
TABLE 1 | Chitosan nanoparticles used as drug delivery systems for viral infections.

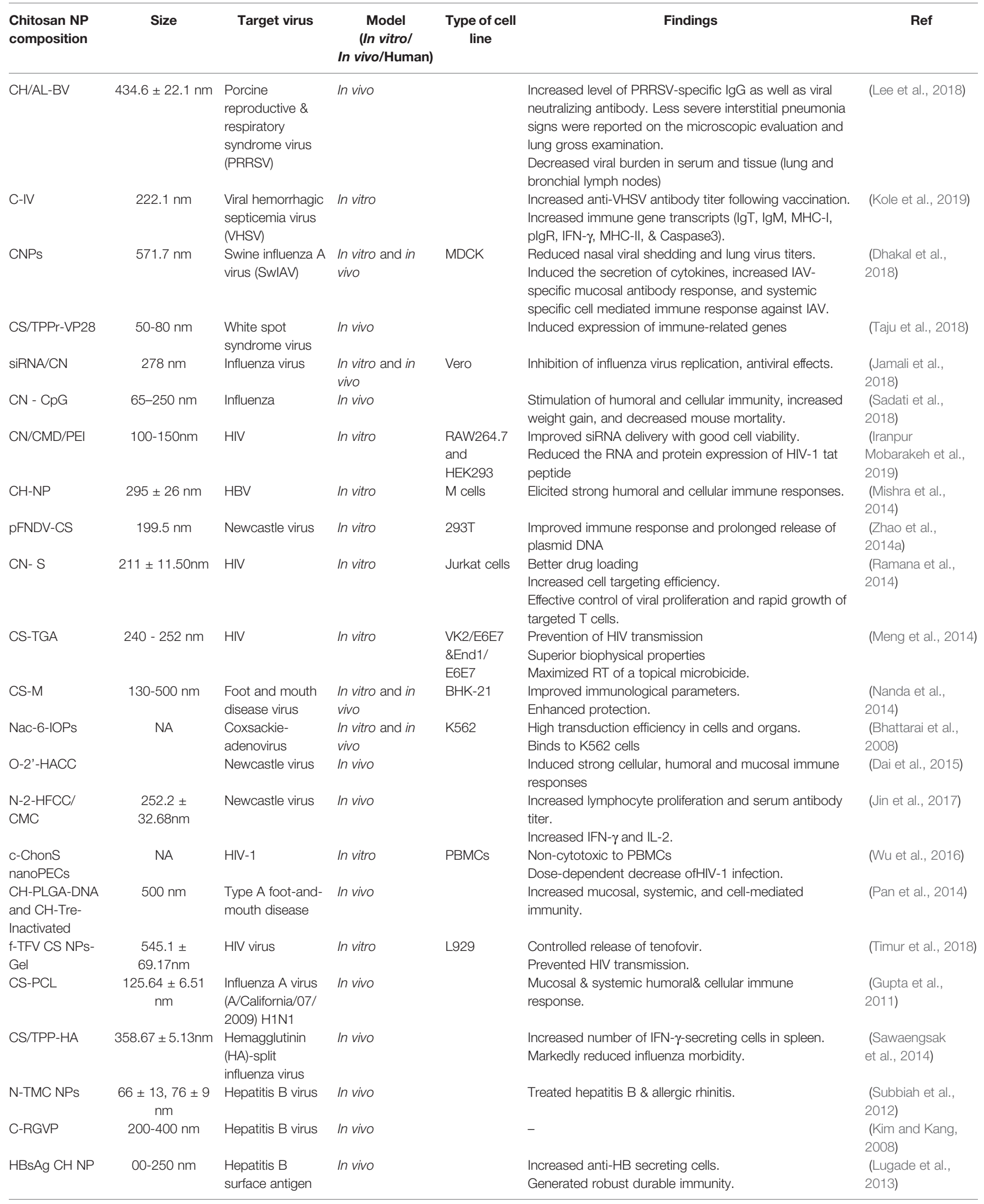


TABLE 1 | Continued

\begin{tabular}{|c|c|c|c|c|c|c|}
\hline $\begin{array}{l}\text { Chitosan NP } \\
\text { composition }\end{array}$ & Size & Target virus & $\begin{array}{c}\text { Model } \\
\text { (In vitro/ } \\
\text { In vivo/Human) }\end{array}$ & $\begin{array}{c}\text { Type of cell } \\
\text { line }\end{array}$ & Findings & Ref \\
\hline
\end{tabular}

\begin{tabular}{|c|c|c|c|c|c|c|}
\hline mPEG-PLA-PEI & $88.9 \mathrm{~nm}$ & Hepatitis B virus & In vitro & PLC/PRF/5 & $\begin{array}{l}\text { Increased Tfh cells (BAFF-R (+) B-cells and CD138 } \\
\text { +plasma cells). } \\
\text { siRNA delivery }\end{array}$ & $\begin{array}{l}\text { (Wang et al., } \\
\text { 2010) }\end{array}$ \\
\hline $\begin{array}{l}\mathrm{CH} \\
\text { nanoemulsion }\end{array}$ & $120-160 \mathrm{~nm}$ & Hepatitis E virus & In vitro & $\begin{array}{l}\text { HeLa \& } \\
\text { THP1 }\end{array}$ & $\begin{array}{l}\text { Good cell uptake and release } \\
\text { No cytotoxicity }\end{array}$ & (Rani et al., 2018) \\
\hline $\begin{array}{l}\text { pFDNA-CS/ } \\
\text { PLGA-NPS }\end{array}$ & $699.1 \pm 5.21 \mathrm{~nm}$ & $\begin{array}{l}\text { Newcastle } \\
\text { disease virus }\end{array}$ & $\begin{array}{l}\text { In vitro and in } \\
\text { vivo }\end{array}$ & $293 \top$ & $\begin{array}{l}\text { Controlled release of plasmid DNA. } \\
\text { Induced strong cellular, humoral, \& mucosal immune } \\
\text { responses. }\end{array}$ & $\begin{array}{l}\text { (Zhao et al., } \\
\text { 2014b) }\end{array}$ \\
\hline $\begin{array}{l}\mathrm{CH}-\mathrm{NS} / \mathrm{MS} \& \\
\mathrm{HTCC}-\mathrm{NS} / \mathrm{MS}\end{array}$ & $60 \mathrm{~nm}$ & $\begin{array}{l}\text { Human corona } \\
\text { viruses, HCoV- } \\
\text { NL63 \&HCoV- } \\
\text { OC43 } \\
\text { Mouse hepatitis } \\
\text { virus (MHV) }\end{array}$ & In vitro & $\begin{array}{l}\text { LLC-MK2, } \\
\text { HCT } 8 \text { \& } \\
\text { LR7 }\end{array}$ & $\begin{array}{l}\text { Genipin used to cross-link } \mathrm{CH} \\
\text { Could be used for concentration of virus from samples } \\
\text { or purification of water supply }\end{array}$ & $\begin{array}{l}\text { (Ciejka et al., } \\
\text { 2017) }\end{array}$ \\
\hline PLGA-CHS NS & $60 \mathrm{~nm}$ & Hepatitis B virus & In vitro & HepG2.2.15 & Able to treat viral hepatitis in-vivo. & (Zeng et al., 2011) \\
\hline $\mathrm{CTS}-\mathrm{Fe}_{3} \mathrm{O}_{4} \mathrm{NPS}$ & NA & $\mathrm{HCV}$ & In vivo & & Increased antibody production and T-cell activity. & (Yang et al., 2011) \\
\hline $\begin{array}{l}\text { NDV/La Sota- } \\
\text { N-2-HACC-NPs }\end{array}$ & $\begin{array}{c}303.88 \pm \\
49.8 \mathrm{~nm}\end{array}$ & $\begin{array}{l}\text { Newcastle } \\
\text { disease viruses }\end{array}$ & In-vitro \& in-vivo & 293- $\mathrm{T}$ & $\begin{array}{l}\text { Increased strong humoral, mucosal and cellular immune } \\
\text { response. }\end{array}$ & (Zhao et al., 2016) \\
\hline $\begin{array}{l}\text { C- QCH4- } \\
\text { dsRNA }\end{array}$ & 400nm & Yellow head virus & In vitro & Sf9 & Effective dsRNA carrier & $\begin{array}{l}\text { (Theerawanitchpan } \\
\text { et al., 2012) }\end{array}$ \\
\hline $\begin{array}{l}\mathrm{CH}-\mathrm{O}- \\
\text { isopropyl-5'-O- } \\
\mathrm{d} 4 \mathrm{~T} \\
\text { monophosphate }\end{array}$ & $166.8 \mathrm{~nm}$ & HIV & In vitro & MT4 & $\begin{array}{l}\text { Prevented leakage of cargo from the NPs before } \\
\text { reaching targeted viral reservoir. }\end{array}$ & (Yang et al., 2010) \\
\hline D- CN & $382 \pm 18 \mathrm{~nm}$ & HIV & In vivo & & Improved delivery system & $\begin{array}{l}\text { (Al-Ghananeem } \\
\text { et al., 2010) }\end{array}$ \\
\hline
\end{tabular}

electrostatic interactions (Kabanov et al., 1996). However, lamivudine (LA) has only very low hydrophobicity, which can be increased by chemical modification. For instance, lamivudine stearate (LAS) was synthesized by esterification of LA with stearic acid by Li et al. (2010). After esterification, the octanol: water distribution coefficient (log P) of LA was increased from -0.95 to 1.82 . Moreover, g- $\mathrm{CH}$ oligosaccharide modified with stearic acid (CSO-SA) formed micelles that could be loaded with LAS showing rapid internalization and accumulation in tumor cells. CSO-SA with a $3.79 \%$ amino substitution degree (SD) showed a critical micellar concentration (CMC) of $0.032 \mathrm{mg} / \mathrm{ml}$, and the micelles of a $1 \mathrm{mg} / \mathrm{ml} \mathrm{CSO-SA}$ concentration showed a mean diameter of $460.8 \mathrm{~nm}$ with a narrow size distribution and zeta potential of $+29.7 \mathrm{mV}$. After LAS loading, the micelle size decreased and the zeta-potential increased. The LAS-loaded CSO-SA micelles (CSO-SA/LAS) showed a $\mathrm{pH}$ dependent release of LA, with a greater release rate at $\mathrm{pH} 7.4$ compared to $\mathrm{pH}$ 6.2. CSO-SA/LAS demonstrated lower cytotoxicity and higher cellular uptake of LA by HBV transfected tumor cells (HepG2.2.15) compared to free LA. The antiHBV activity of CSO-SA/LAS in vitro showed higher inhibition of antigen expression and DNA replication, in comparison to LAS and LA alone (Li et al., 2010).

Dhakal et al. (2018) assessed the immune response and crossprotective efficiency of inactivated SwIAV vaccine encapsulated in chitosan NPs and delivered via the IN route to pigs. Killed or inactivated SwIAV H1N2 ( $\delta$-lineage) virus antigens (KAg) were encapsulated in the $\mathrm{CH}$ NPs to form CNPs-KAg which was administered twice as an IN mist to nursery pigs. Vaccinated and control animals were challenged with a SwIAV H1N1 $(\gamma$ lineage). The pigs vaccinated with the CNPs-KAg showed elevated serum IgG antibodies and more mucosal IgA secretion in the nasal swabs, broncho-alveolar lavage (BAL) fluids as well as lung lysates. Protection was achieved against homologous (H1N2), heterologous (H1N1), and hetero-subtype (H3N2) influenza A-virus strains. Before the challenge, they found higher levels of cytotoxic-T lymphocyte proliferation, antigen specific lymphocyte proliferation, and IFN- $\gamma$ secretion from peripheral blood mononuclear cells, in pigs immunized with CNPs-KAg compared to controls vaccinated with KAg alone. When CNP-KAg vaccinated pigs were challenged with the heterologous virus, the microscopic and macroscopic pulmonary lesions were reduced. Notably, titers of SwIAV in nasal swabs and BAL fluid were substantially reduced in pigs vaccinated with CNPs-KAg, but not in the KAg control group. Also, an increased frequency of helper $\mathrm{T}$ memory cells and an increase in IFN $\gamma$ secretion in bronchial lymph nodes were observed. The SwIAV CH nanovaccine delivered by the IN route triggered IgA and cross-protective mucosal cellular immune responses in the respiratory tract, leading to lower virus titers in the nose and lungs. They suggested that the chitosan-based nanovaccine for influenza might be useful for commercial pig farms, and could be tested for human influenza vaccination (Dhakal et al., 2018).

Table 2 lists some chitosan nanoparticles that have been used for improving vaccination against viral infections. 
TABLE 2 | Chitosan nanoparticles investigated for vaccination against viral infections.

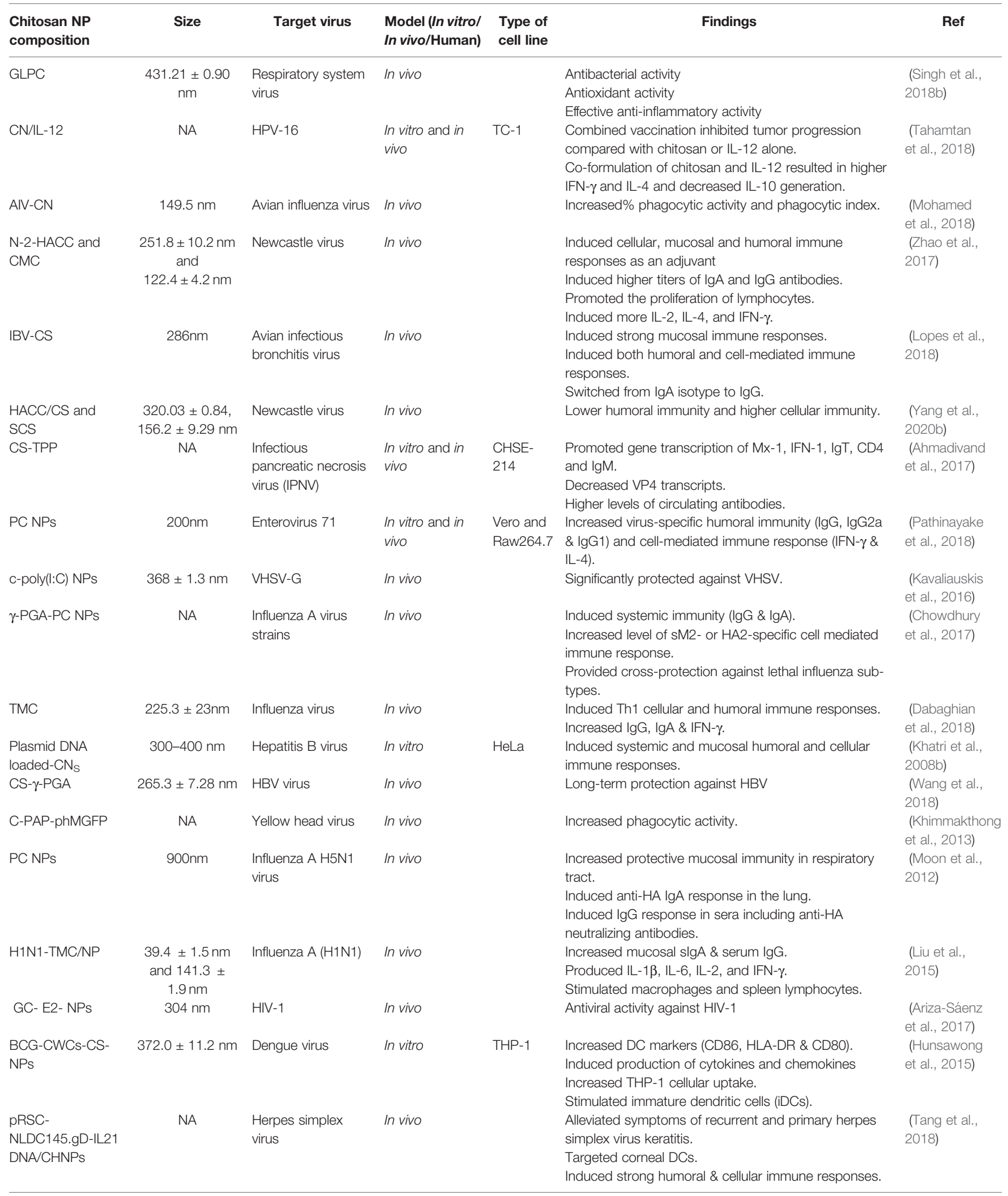


TABLE 2 | Continued

\begin{tabular}{|c|c|c|c|c|c|c|}
\hline $\begin{array}{l}\text { Chitosan NP } \\
\text { composition }\end{array}$ & Size & Target virus & $\begin{array}{l}\text { Model (In vitro/ } \\
\text { In vivo/Human) }\end{array}$ & $\begin{array}{l}\text { Type of } \\
\text { cell line }\end{array}$ & Findings & Ref \\
\hline $\begin{array}{l}\text { pVAX(HBc)DNA- } \\
\mathrm{CH} \text { NPs }\end{array}$ & $271.1 \pm 6.5 n m$ & Hepatitis B Virus & In vivo & & $\begin{array}{l}\text { Enhanced immunogenicity. } \\
\text { Increased antibody production, IFN- } \gamma \text { secretion, } \\
\text { antigen-specific cell lysis. }\end{array}$ & $\begin{array}{l}\text { (Jiang et al., } \\
\text { 2007) }\end{array}$ \\
\hline $\mathrm{CN}_{\mathrm{S}}$ & $200 \mathrm{~nm}$ & Hepatitis B virus & In-vitro \& In-vivo & $\begin{array}{l}\text { RAW } \\
264.7\end{array}$ & $\begin{array}{l}\text { Delivered imiquimod\& recombinant HBV surface } \\
\text { antigen } \\
\text { Increased proinflammatory cytokines TNF- } \alpha \text { \& IL-6. } \\
\text { Enhanced IgG over time and specific immunological } \\
\text { memory. } \\
\text { Balanced cellular \&humoral responses }\end{array}$ & $\begin{array}{l}\text { Nicente et al., } \\
\text { 2013) }\end{array}$ \\
\hline $\mathrm{CH}(\mathrm{W}+\mathrm{CpG})$ & $581.1 \pm 32.6 \mathrm{~nm}$ & Influenza virus & In vivo & & $\begin{array}{l}\text { Increased hemagglutination inhibition }(\mathrm{HI}) \text { antibody titer } \\
\text { Increased } \operatorname{slgA} \text { and IgG titers } \\
\text { Stimulated IFN- } \gamma \text { \& IL-2 secretion }\end{array}$ & $\begin{array}{l}\text { (Dehghan } \\
\text { et al., 2014) }\end{array}$ \\
\hline $\begin{array}{l}\text { N,N,N-trimethyl } \\
\text { chitosan (TMC) }\end{array}$ & $200-220 \mathrm{~nm}$ & Influenza virus & In vivo & & $\begin{array}{l}\text { Increased lgG1, IgG2a/c and lgG responses } \\
\text { Improved immunogenicity and protected against viral } \\
\text { challenge. }\end{array}$ & $\begin{array}{l}\text { (Hagenaars } \\
\text { et al., 2009b) }\end{array}$ \\
\hline $\begin{array}{l}\text { Chitosan-pJME/ } \\
\text { GM-CSF NPs }\end{array}$ & $108.3 \mathrm{~nm}$ & $\begin{array}{l}\text { Japanese } \\
\text { encephalitis virus }\end{array}$ & In vivo & & Increased splenic DC activity \& cell mediated immunity. & $\begin{array}{l}\text { (Zhai et al., } \\
\text { 2015) }\end{array}$ \\
\hline $\begin{array}{l}\text { Chitosan-JEV DNA } \\
\text { vaccines }\end{array}$ & $200 \mathrm{~nm}$ & $\begin{array}{l}\text { Japanese } \\
\text { encephalitis virus }\end{array}$ & In vivo & & Activated DCs in hair follicles \& epidermis. & $\begin{array}{l}\text { (Huang et al., } \\
\text { 2009) }\end{array}$ \\
\hline $\begin{array}{l}\text { pCAGG-ChIL2 } \\
\text { CNPs }\end{array}$ & 100 and $200 \mathrm{~nm}$ & $\begin{array}{l}\text { Newcastle disease } \\
\text { virus (NDV) }\end{array}$ & In vivo & & $\begin{array}{l}\text { Increased hemagglutination inhibition antibody titer\& } \\
\text { serum IFN- } \gamma \text {. }\end{array}$ & $\begin{array}{l}\text { (Zhang et al., } \\
\text { 2010) }\end{array}$ \\
\hline
\end{tabular}

\section{CHITOSAN VEHICLES FOR DELIVERY OF RNA-BASED THERAPEUTICS}

As mentioned earlier, nucleic acid-based drugs have been introduced as a treatment for various conditions. Nucleic acidbased drugs can be divided into two main groups called doublestranded RNA-mediated interference (RNAi) and antisense oligonucleotides (ASO) (Chery, 2016). RNAi is used for posttranscriptional gene silencing, mediated by ribonucleases in combination with other complexes and enzymes that cleave the targeted messenger RNA into small segments (Agrawal et al., 2003). Antisense oligonucleotides bind to the respective target nucleic acids by Watson-Crick base pairing, which inhibits or alters gene expression through splicing modification, target degradation, steric hindrance, etc. In contrast to small molecules drugs, that work by binding to proteins with frequent off-target toxic side effects (Sharma et al., 2014), RNA-based drugs are much more specific by targeting individual nucleic acids. Nucleic acids based drugs have more specificity, lower toxicity, and higher activity. Two major diseases, spinal muscular atrophy (SMA) and Duchenne muscular dystrophy (DMD) are good examples of those conditions, which have received approval for treatment by these approaches (Kole et al., 2012). Although RNA-based drugs enjoy enormous potential, some potential challenges should be considered. For example, RNAs have been proven to be innately unstable. Hence, delivering nucleic acids in quantity to the target tissues is difficult because of nuclease-mediated degradation in the circulation and clearance by renal excretion (Moreno and Pêgo, 2014). Moreover, some other issues such as toxicity as a result of over-activation of the immune system, as well as off-targeting effects should be investigated (Davidson and McCray, 2011).

The ease of chemical modification of chitosan, as well as the possibility to tailor its structural and functional properties, are due to the plentiful hydroxyl and amino groups in the $\mathrm{CH}$ chains (Singh et al., 2014). The amino groups are responsible for the positive charge formed at $\mathrm{pH}<6$, that equates to the $\mathrm{pH}$ of tumoral extra-cellular medium. Nevertheless, the cationic charge of $\mathrm{CH}$ disappears at the physiological $\mathrm{pH}$ of the blood, resulting in lower NP stability, and poor efficiency in siRNA complex formation. Stability is a key concern for in vivo gene silencing applications, along with interactions with various serum proteins after systemic delivery (Ragelle et al., 2013). Nonetheless, because positively charged $\mathrm{CH}$ is a natural polymeric structure, it has been widely explored for the delivery of nucleic acids (Zhang et al., 2013). A key advantage is the strong electrostatic interactions with the negatively charged RNA, which creates stable polyplexes. In addition, the siRNA binding activity of $\mathrm{CH}$ is clearly higher than other natural polysaccharides, that commonly possess negative or neutral charges. For instance, another natural polysaccharide, hyaluronic acid required to be to be chemically modified to become a cationic polymer in order to be applied in the delivery of nucleic acids (Serrano-Sevilla et al., 2019).

In one study, Wang et al. used nano-precipitation and solvent evaporation procedures to prepare four types of cationic NPs for delivery of siRNA to target HBV virus infections. Poly(D,Llactide-co-glycolide) (PGLA) or mPEG-PLA was attached to either PEI or $\mathrm{CH}$ as a surface coating, and the size and size distribution of the NPs were measured by laser scattering, surface charge by zeta potential, and surface chemistry by X-ray electron spectroscopy (XPS). The mPEG-PLA-PEI NPs showed the best siRNA transfection efficiency and the highest inhibition of the expression of HBV surface antigen (Wang et al., 2010).

Another research group created $\mathrm{CH} / \mathrm{siRNA}$ NPs as a possible treatment option against influenza virus infections in vivo and in vitro (Jamali et al., 2018). They formulated a siRNA sequence against influenza nucleoprotein, incorporated with $\mathrm{CH}$ polymer as a siRNA/chitosan NP complex. They used dynamic light 
scattering to measure the NP zeta-potential and size. Fluorescence microscopy was used to visualize the uptake of the labeled siRNA into Vero-cells. Flow cytometry was used to analyze and quantify the NP-mediated knockdown of the enhanced green fluorescent protein (EGFP) gene in Vero cells. The CH/siRNA NPs were efficiently taken up by Vero cells, and inhibited the replication of influenza virus. Nasal delivery of the siRNA using the CH-NP complex showed anti-viral activity, resulting in significant protection of BALB/c mice from a lethal influenza challenge. They concluded that $\mathrm{CH}$ NPs equipped with siRNA had the potential to control influenza virus infections (Jamali et al., 2018).

MiRNA-based therapeutics are being investigated to restore the expression of down-regulated miRNAs, or inhibit the expression of unwanted mRNAs (Chaudhary et al., 2018). For example, McKiernan et al. explored the treatment of cystic fibrosis using a miRNA-based nanomedicine. These researchers utilized a nano-delivery system composed of cytosine and PEI for targeting of miR-126 (McKiernan and Greene, 2015). Moreover, Deng et al. described the delivery of a combination of miR-34a plus doxorubicin (DOX) to treat breast cancer employing hyaluronic acid-CH-NPs (Deng et al., 2014). Louw et al. used CH-mediated delivery of miRNA-124 to reduce the number and activation state of microglial cells in spinal cord injuries in rats (Louw et al., 2016).

Chitosan-based nanocarriers are expected to be useful for the delivery of small interfering RNAs, microRNAs, or antisense oligonucleotides, as a molecular targeted therapy in the near future.

\section{CONCLUSIONS}

Nanomedicines are being increasingly used for drug delivery, with many advantages, including tissue targeting, controlled release, improved permeability and solubility of drugs, greater effectiveness, improved safety, and lower toxicity. Naturally occurring materials are often preferred for the construction of these nanomedicines, compared to synthetic polymers, inorganic materials, or carbon-based nanomaterials. The bio-pharmaceutical properties of these natural nanomedicines, include low toxicity, and improvements in cell uptake, biodistribution, metabolism, and excretion. The possible long-term accumulation of nonbiodegradable nanoparticles in tissue and organs, has led to some concerns about possible carcinogenicity and genotoxicity. Metallic NPs (gold and silver), carbon-based NPs (carbon nanotubes and graphene), and inorganic NPs (silica and titania) have all been faced with these worries and concerns. On the other hand, there have been many naturally occurring biodegradable materials that have been used to prepare various types of nanostructures, including proteins, peptides, lipids, and polysaccharides such as cellulose. Nevertheless, we believe that chitosan is one of the most promising types of naturally occurring materials in the nanomedicine arena. This preference is based on the well-known lack of toxicity of chitosan, as illustrated by the fact that chitosan is a food ingredient and is widely consumed by human beings as a health-food supplement. Another very important property of chitosan is its mucoadhesive ability that allows CH NPs to be administered by transmucosal routes, such as intranasal, intraocular, intravaginal, intratracheal or intrapulmonary etc. This ability is highly relevant when it comes to consider viral diseases, which often gain entry to the human body via a mucosal route.

Viral infections are a universal challenge to the human race that affect the health and economic well-being of millions of people, and cause disability, suffering, and death throughout the world. Treatment of viral infections has been challenging because viruses hijack the host cells in order to proliferate, and killing the virus often means killing the host cell as well. Some antiviral drugs have been developed based on nucleoside analogs and inhibitors of viral-specific enzymes. However, drug resistance often emerges due to the ability of viruses to undergo relatively facile mutations. Drug resistance is considered to be a significant threat to public health, leading to an increase in mortality and medical expenses. Infectious virus particles (virions) attach to specific receptors on susceptible cells leading to their entrance, and establishment of a viral infection. Viruses can spread within the body by local invasion, or by long distance transport via the bloodstream, lymphatics, or neuronal pathways. Cell-to-cell transmission of infectious viruses involves the direct export of the infectious particles out of the cell into the extra-cellular environment. The virus particles can be transported along nerve cells and spread to epithelial cells.

In addition to anti-viral drugs, vaccines are an important therapeutic approach that can not only prevent the development of a viral infection, but can also decrease the severity of the infection once it has become established. Vaccines have been proved to be highly effective against many viral infections, but many vaccines are poorly effective or even completely ineffective. The reasons for this lack of universal efficacy are manifold, and some are still under investigation. For this reason many groups have studied the use of various NPs to deliver different kinds of vaccines, whether they be whole inactivated viruses, recombinant viral antigens, or DNA and RNA sequences. Moreover, the NPs themselves can act as an adjuvant, by increasing the uptake of the vaccine by antigen presenting cells. Additional adjuvants can be combined with the vaccine inside the NPs to further improve the immunogenicity.

Chitosan-based NPs have an intrinsic positive charge, which can interact with the negative charge present on call membrane and on mucosal surfaces accounting for its mucoadhesive properties. This is useful because delivering the vaccines across the mucosal surface allows the induction of specific mucosal immunity characterized by secretion of IgA antibodies as well as IgG and IgM. Moreover the mucosal-associated lymphoid tissue (MALT) can be activated by vaccines encapsulated in $\mathrm{CH}$ NPs and delivered to the mucosal surface, particularly by the intranasal administration route.

Chitosan-based nanocarriers show many advantageous properties, such as nanoscale dimensions, high surface area to volume ratio, as well as the ability to tailor the surface charge and attach targeting ligands. Moreover, the chitosan matrix is able to 
incorporate a wide variety of different types of cargo, including antiviral drugs, proteins, peptides, nucleic acids, and even whole inactivated viruses. One relatively new approach to treating viral infections is based on gene silencing. Gene silencing uses small interfering RNAs, microRNAs, or antisense oligonucleotides, all of which can be loaded into CH NPs. The idea is to recognize the 3'-untranslated region of the viral mRNA to allow it to be degraded by the RNA-induced silencing complex (RISC). Chitosan nanostructures are also able to cross biological barriers such as the blood-brain barrier (BBB). CH NPs can increase drug or gene delivery to the site of the viral infection and also improve the cellular uptake.

As mentioned earlier, $\mathrm{CH}$-based carriers enjoy increasing popularity due to their many advantages. Nonetheless, they still suffer from several limitations, like poor solubility at the physiological $\mathrm{pH}$, premature release in the cytoplasm, as well as questions about the stability of the complexes following cellular uptake. Therefore, it is necessary to discover further improvements in $\mathrm{CH}$-based nanocarriers. Researchers have employed chemical modification of $\mathrm{CH}$ using PEG (PEGylation) to improve $\mathrm{CH}$ solubility, although excessive PEGylation can

\section{REFERENCES}

Abd Elgadir, M., Uddin, Md S., Ferdosh, S., Adam, A., Chowdhury, A. J. K., and Sarker, Md Z. I. (2015). Impact of chitosan composites and chitosan nanoparticle composites on various drug delivery systems: A review. J. Food Drug Anal. 23, 619-629. doi: 10.1016/j.jfda.2014.10.008

Agrawal, N., Dasaradhi, P. V., Mohmmed, A., Malhotra, P., Bhatnagar, R. K., and Mukherjee, S. K. (2003). RNA interference: biology, mechanism, and applications. Microbiol. Mol. Biol. Rev. 67, 657-685. doi: 10.1128/MMBR. 67.4.657-685.2003

Ahmadivand, S., Soltani, M., Behdani, M., Evensen, Ø., Alirahimi, E., Hassanzadeh, R., et al. (2017). Oral DNA vaccines based on CS-TPP nanoparticles and alginate microparticles confer high protection against infectious pancreatic necrosis virus (IPNV) infection in trout. Dev. Comp. Immunol. 74, 178-189. doi: 10.1016/j.dci.2017.05.004

Akagi, T., Higashi, M., Kaneko, T., Kida, T., and Akashi, M. (2005). In vitro enzymatic degradation of nanoparticles prepared from hydrophobicallymodified poly ( $\gamma$-glutamic acid). Macromol. Biosci. 5, 598-602. doi: 10.1002/ mabi.200500036

Alexis, F., Pridgen, E., Molnar, L. K., and Farokhzad, O. C. (2008). Factors affecting the clearance and biodistribution of polymeric nanoparticles. Mol. Pharm. 5, 505-515. doi: $10.1021 / \mathrm{mp} 800051 \mathrm{~m}$

Al-Ghananeem, A. M., Saeed, H., Florence, R., Yokel, R. A., and Malkawi, A. H. (2010). Intranasal drug delivery of didanosine-loaded chitosan nanoparticles for brain targeting; an attractive route against infections caused by AIDS viruses. J. Drug Target 18, 381-388. doi: 10.3109/10611860903483396

Al-Qadi, S., Grenha, A., and Remuñán-López, C. (2011). Microspheres loaded with polysaccharide nanoparticles for pulmonary delivery: Preparation, structure and surface analysis. Carbohydr. Polymers 86, 25-34. doi: 10.1016/ j.carbpol.2011.03.022

Andrews, W. W., Kimberlin, D. F., Whitley, R., Cliver, S., Ramsey, P. S., and Deeter, R. (2006). Valacyclovir therapy to reduce recurrent genital herpes in pregnant women. Am. J. Obstet. Gynecol. 194, 774-781. doi: 10.1016/j.ajog.2005.11.051

Ansari, R., Sadati, S. M., Mozafari, N., Ashrafi, H., and Azadi, A. (2020). Carbohydrate Polymer-Based Nanoparticle Application in Drug Delivery for CNS-Related Disorders. Eur. Polymer J. 128, 109607.

Ariza-Sáenz, M., Espina, M., Bolaños, N., Calpena, A. C., Gomara, M. J., Haro, I., et al. (2017). Penetration of polymeric nanoparticles loaded with an HIV-1 inhibitor peptide derived from GB virus $\mathrm{C}$ in a vaginal mucosa model. Eur. J. Pharm. Biopharm. 120, 98-106. doi: 10.1016/j.ejpb.2017.08.008 decrease the density of the positive charges on $\mathrm{CH}$, and lower its ability to bind to nucleic acids. Furthermore, chemical modification made to the siRNA itself may enhance the stability of the NPs, although this approach can make the siRNA activity less efficient. The addition of other components with a negative charge has been proposed to increase the stability of the CH NPs to improve gene silencing. $\mathrm{CH}$ NPs often show a higher encapsulation efficiency (EE\%), and the ability for sustained release after uptake into the cells. Additional experiments are warranted in animal models of diseases such as viral infections and unwanted fibrosis. However, future researchers must optimize the $\mathrm{CH}$ modification procedures for full realization.

\section{AUTHOR CONTRIBUTIONS}

$\mathrm{HM}$ and $\mathrm{MH}$ contributed in conception, design, statistical analysis and drafting of the manuscript. $\mathrm{HB}, \mathrm{FB}, \mathrm{SM}, \mathrm{ZS}$, JS, $\mathrm{MN}, \mathrm{HB}, \mathrm{BB}, \mathrm{MA}-\mathrm{K}$, and MG contributed in data collection and manuscript drafting. All authors contributed to the article and approved the submitted version.
Artan, M., Karadeniz, F., Karagozlu, M. Z., Kim, M.-M., and Kim, S.-K. (2010). Anti-HIV-1 activity of low molecular weight sulfated chitooligosaccharides. Carbohydr. Res. 345, 656-662. doi: 10.1016/j.carres.2009.12.017

Asselah, T., Ripault, M.-P., Castelnau, C., Giuily, N., Boyer, N., and Marcellin, P. (2005). The current status of antiviral therapy of chronic hepatitis B. J. Clin. Virol. 34, S115-SS24.

Badawy, M. E. I., and Rabea, E. I. (2011). A biopolymer chitosan and its derivatives as promising antimicrobial agents against plant pathogens and their applications in crop protection. Int. J. Carbohydr. Chem. 2011.

Balmayor, E. R., Baran, E. T., Azevedo, H. S., and Reis, R. L. (2012). Injectable biodegradable starch/chitosan delivery system for the sustained release of gentamicin to treat bone infections. Carbohydr. Polymers 87, 32-39. doi: 10.1016/j.carbpol.2011.06.078

Beisel, C., Addo, M. M., and zur Wiesch, J. S. (2020). Seroconversion of HBsAG coincides with hepatitis A super-infection: A case report. World J. Clin. cases 8, 1651. doi: 10.12998/wjcc.v8.i9.1651

Bernkop-Schnürch, A., and Dünnhaupt, S. (2012). Chitosan-based drug delivery systems. Eur. J. Pharmaceutics Biopharm. 81, 463-469. doi: 10.1016/ j.ejpb.2012.04.007

Bhattarai, S. R., Kim, S. Y., Jang, K. Y., Lee, K. C., Yi, H. K., Lee, D. Y., et al. (2008). $\mathrm{N}$-hexanoyl chitosan-stabilized magnetic nanoparticles: enhancement of adenoviral-mediated gene expression both in vitro and in vivo. Nanomedicine 4, 146-154. doi: 10.1016/j.nano.2008.02.001

Bowman, M. C., Ballard, T. E., Ackerson, C. J., Feldheim, D. L., Margolis, D. M., and Melander, C. (2008). Inhibition of HIV fusion with multivalent gold nanoparticles. J. Am. Chem. Soc. 130, 6896-6897. doi: 10.1021/ja710321g

Bramwell, V. W., and Perrie, Y. (2006). Particulate delivery systems for vaccines: what can we expect? J. Pharm. Pharmacol. 58, 717-728. doi: 10.1211/ jpp.58.6.0002

Brunel, F., Véron, L., David, L., Domard, A., and Delair, T. (2008). A novel synthesis of chitosan nanoparticles in reverse emulsion. Langmuir 24, 1137011377. doi: 10.1021/la801917a

Calderón, L., Harris, R., Cordoba-Diaz, M., Elorza, M., Elorza, B., Lenoir, J., et al. (2013). Nano and microparticulate chitosan-based systems for antiviral topical delivery. Eur. J. Pharm. Sci. 48, 216-222. doi: 10.1016/j.ejps. 2012.11.002

Calvo, P., Remunan-Lopez, C., Vila-Jato, J. L., and Alonso, M. J. (1997). Novel hydrophilic chitosan-polyethylene oxide nanoparticles as protein carriers. J. Appl. Polymer Sci. 63, 125-132. doi: 10.1002/(SICI)1097-4628(19970103) 63:1<125::AID-APP13>3.0.CO;2-4 
Caron, J., Reddy, L. H., Lepêtre-Mouelhi, S., Wack, S., Clayette, P., Rogez-Kreuz, C., et al. (2010). Squalenoyl nucleoside monophosphate nanoassemblies: new prodrug strategy for the delivery of nucleotide analogues. Bioorg. Med. Chem. Lett. 20, 2761-2764. doi: 10.1016/j.bmcl.2010.03.070

Chaudhary, V., Jangra, S., and Yadav, N. R. (2018). Nanotechnology based approaches for detection and delivery of microRNA in healthcare and crop protection. J. Nanobiotechnol. 16, 40. doi: 10.1186/s12951-018-0368-8

,Cheba, B. A. (2011). Chitin and chitosan: marine biopolymers with unique properties and versatile applications. Global J. Biotechnol. Biochem. 6, 149-153.

Chen, J. L., and Zhao, Y. (2012). Effect of molecular weight, acid, and plasticizer on the physicochemical and antibacterial properties of $\beta$-chitosan based films. J. Food Sci. 77, E127-EE36.

Chery, J. (2016). RNA therapeutics: RNAi and antisense mechanisms and clinical applications. Postdoc. J. 4, 35-50. doi: 10.14304/SURYA.JPR.V4N7.5

Chiappetta, D. A., Facorro, G., de Celis, E. R., and Sosnik, A. (2011). Synergistic encapsulation of the anti-HIV agent efavirenz within mixed poloxamine/ poloxamer polymeric micelles. Nanomedicine 7, 624-637. doi: 10.1016/ j.nano.2011.01.017

Chirkov, S. N. (2002). The antiviral activity of chitosan. Appl. Biochem. Microbiol. 38, 1-8. doi: 10.1023/A:1013206517442

Chowdhury, M. Y. E., Kim, T. H., Uddin, M. B., Kim, J. H., Hewawaduge, C. Y., Ferdowshi, Z., et al. (2017). Mucosal vaccination of conserved sM2, HA2 and cholera toxin subunit A1 (CTA1) fusion protein with poly gamma-glutamate/ chitosan nanoparticles (PC NPs) induces protection against divergent influenza subtypes. Vet. Microbiol. 201, 240-251. doi: 10.1016/j.vetmic. 2017.01.020

Ciejka, J., Wolski, K., Nowakowska, M., Pyrc, K., and Szczubiałka, K. (2017). Biopolymeric nano/microspheres for selective and reversible adsorption of coronaviruses. Mater. Sci. Eng. C. Mater. Biol. Appl. 76, 735-742. doi: 10.1016/ j.msec.2017.03.047

Cosgrove, S. E. (2006). The relationship between antimicrobial resistance and patient outcomes: mortality, length of hospital stay, and health care costs. Clin. Infect. Dis. 42 Suppl 2, S82-S89. doi: 10.1086/499406

Costantino, H. R., Illum, L., Brandt, G., Johnson, P. H., and Quay, S. C. (2007). Intranasal delivery: physicochemical and therapeutic aspects. Int. J. Pharmaceutics 337, 1-24. doi: 10.1016/j.ijpharm.2007.03.025

Crisci, E., Mussá, T., Fraile, L., and Montoya, M. (2013). Influenza virus in pigs. Mol. Immunol. 55, 200-211. doi: 10.1016/j.molimm.2013.02.008

Dabaghian, M., Latifi, A. M., Tebianian, M., NajmiNejad, H., and Ebrahimi, S. M. (2018). Nasal vaccination with r4M2e.HSP70c antigen encapsulated into Ntrimethyl chitosan (TMC) nanoparticulate systems: Preparation and immunogenicity in a mouse model. Vaccine 36, 2886-2895. doi: 10.1016/ j.vaccine.2018.02.072

Dai, C., Kang, H., Yang, W., Sun, J., Liu, C., Cheng, G., et al. (2015). O-2'hydroxypropyltrimethyl ammonium chloride chitosan nanoparticles for the delivery of live Newcastle disease vaccine. Carbohydr. Polym. 130, 280-289. doi: 10.1016/j.carbpol.2015.05.008

das Neves, J., Amiji, M. M., Bahia, M. F., and Sarmento, B. (2010). Nanotechnology-based systems for the treatment and prevention of HIV/ AIDS. Advanced Drug Delivery Rev. 62, 458-477. doi: 10.1016/j.addr. 2009.11.017

Davidson, B. L., and McCray, P. B. Jr. (2011). Current prospects for RNA interference-based therapies. Nat. Rev. Genet. 12, 329-340. doi: 10.1038/nrg2968

de Britto, D., de Moura, M. R., Aouada, F. A., Mattoso, L. H. C., and Assis, O. B. G. (2012). N, N, N-trimethyl chitosan nanoparticles as a vitamin carrier system. Food Hydrocolloids 27, 487-493. doi: 10.1016/j.foodhyd.2011.09.002

De Jong, M. D., Thanh, T. T., Khanh, T. H., Hien, V. M., Smith, G. J. D., Chau, N. V., et al. (2005). Oseltamivir resistance during treatment of influenza A (H5N1) infection. New Engl. J. Med. 353, 2667-2672. doi: 10.1056/ NEJMoa054512

Dehghan, S., Tafaghodi, M., Bolourieh, T., Mazaheri, V., Torabi, A., Abnous, K., et al. (2014). Rabbit nasal immunization against influenza by dry-powder form of chitosan nanospheres encapsulated with influenza whole virus and adjuvants. Int. J. Pharm. 475, 1-8. doi: 10.1016/j.ijpharm.2014.08.032

Deng, X., Cao, M., Zhang, J., Hu, K., Yin, Z., Zhou, Z., et al. (2014). Hyaluronic acid-chitosan nanoparticles for co-delivery of MiR-34a and doxorubicin in therapy against triple negative breast cancer. Biomaterials 35, 4333-4344. doi: 10.1016/j.biomaterials.2014.02.006
Dhakal, S., Renu, S., Ghimire, S., Shaan Lakshmanappa, Y., Hogshead, B. T., Feliciano-Ruiz, N., et al. (2018). Mucosal Immunity and Protective Efficacy of Intranasal Inactivated Influenza Vaccine Is Improved by Chitosan Nanoparticle Delivery in Pigs. Front. Immunol. 9, 934. doi: 10.3389/fimmu.2018.00934

Divya, K., and Jisha, M. S. (2018). Chitosan nanoparticles preparation and applications. Environ. Chem. Lett. 16, 101-112. doi: 10.1007/s10311-0170670-y

Donalisio, M., Leone, F., Civra, A., Spagnolo, R., Ozer, O., Lembo, D., et al. (2018). Acyclovir-loaded chitosan nanospheres from nano-emulsion templating for the topical treatment of herpesviruses infections. Pharmaceutics 10, 46. doi: 10.3390/pharmaceutics10020046

D'Affronte, L., and Platia, C.L. (2020). Overview of Infectious Diseases of Concern to Dental Practitioners: Other Viral Infections. In: DePaola, L.Grant, L. (eds) Infection Control in the Dental Office. (Cham: Springer). doi: 10.1007/978-3030-30085-2_3

Dykhuis-Haden, C., Painter, T., Fangman, T., and Holtkamp, D. (2012). Assessing production parameters and economic impact of swine influenza, PRRS and Mycoplasma hyopneumoniae on finishing pigs in a large production system. Denver: Am. Assoc. Swine Veterinarians, 75-76.

Einbu, A., and Vårum, K. M. (2008). Characterization of chitin and its hydrolysis to GlcNAc and GlcN. Biomacromolecules 9, 1870-1875. doi: 10.1021/ bm8001123

El-Shabouri, M. H. (2002). Positively charged nanoparticles for improving the oral bioavailability of cyclosporin-A. Int. J. Pharmaceutics 249, 101-108. doi: 10.1016/S0378-5173(02)00461-1

Erbacher, P., Zou, S., Bettinger, T., Steffan, A.-M., and Remy, J.-S. (1998). Chitosan-based vector/DNA complexes for gene delivery: biophysical characteristics and transfection ability. Pharm. Res. 15, 1332-1339. doi: 10.1023/A:1011981000671

Franca, E. F., Lins, R. D., Freitas, L. C. G., and Straatsma, T. P. (2008). Characterization of chitin and chitosan molecular structure in aqueous solution. J. Chem. Theory Comput. 4, 2141-2149. doi: 10.1021/ct8002964

Funkhouser, J. D., and Aronson, N. N. (2007). Chitinase family GH18: evolutionary insights from the genomic history of a diverse protein family. BMC Evol. Biol. 7, 96. doi: 10.1186/1471-2148-7-96

Gabizon, A., Catane, R., Uziely, B., Kaufman, B., Safra, T., Cohen, R., et al. (1994). Prolonged circulation time and enhanced accumulation in malignant exudates of doxorubicin encapsulated in polyethylene-glycol coated liposomes. Cancer Res. 54, 987-992.

Gabor, F., Schwarzbauer, A., and Wirth, M. (2002). Lectin-mediated drug delivery: binding and uptake of BSA-WGA conjugates using the Caco-2 model. Int. J. Pharmaceutics 237, 227-239. doi: 10.1016/S0378-5173(02)00049-2

Gagliardi, M. (2017). Biomimetic and bioinspired nanoparticles for targeted drug delivery. Ther. Delivery 8, 289-299. doi: 10.4155/tde-2017-0013

Gao, Y., Liu, W., Wang, W., Zhang, X., and Zhao, X. (2018). The inhibitory effects and mechanisms of 3, 6-O-sulfated chitosan against human papillomavirus infection. Carbohydr. Polymers 198, 329-338. doi: 10.1016/j.carbpol.2018.06.096

Garg, U., Chauhan, S., Nagaich, U., and Jain, N. (2019). Current advances in chitosan nanoparticles based drug delivery and targeting. Adv. Pharm. Bull. 9, 195. doi: 10.15171/apb.2019.023

Giri, N., Tomar, P., Karwasara, V. S., Pandey, R. S., and Dixit, V. K. (2011). Targeted novel surface-modified nanoparticles for interferon delivery for the treatment of hepatitis B. Acta Biochim. Biophys. Sin. 43, 877-883. doi: 10.1093/ abbs/gmr082

Glück, R., Mischler, R., Durrer, P., Fürer, E., Lang, A. B., Herzog, C., et al. (2000). Safety and immunogenicity of intranasally administered inactivated trivalent virosome-formulated influenza vaccine containing Eschevichia coli HeatLabile Toxin as a Mucosal Adjuvant. J. Infect. Dis. 181, 1129-1132. doi: $10.1086 / 315337$

Goldberg, M., Langer, R., and Jia, X. (2007). Nanostructured materials for applications in drug delivery and tissue engineering. J. Biomater. Sci. Polym. Ed 18, 241-268. doi: 10.1163/156856207779996931

Gupta, P. N., Mahor, S., Rawat, A., Khatri, K., Goyal, A., and Vyas, S. P. (2006). Lectin anchored stabilized biodegradable nanoparticles for oral immunization: 1. Development and in vitro evaluation. Int. J. Pharmaceutics 318, 163-173. doi: 10.1016/j.ijpharm.2006.03.017

Gupta, N. K., Tomar, P., Sharma, V., and Dixit, V. K. (2011). Development and characterization of chitosan coated poly-( $\varepsilon$-caprolactone) nanoparticulate 
system for effective immunization against influenza. Vaccine 29, 9026-9037. doi: $10.1016 /$ j.vaccine.2011.09.033

Gupta, U., and Jain, N. K. (2010). Non-polymeric nano-carriers in HIV/AIDS drug delivery and targeting. Advanced Drug Delivery Rev. 62, 478-490. doi: 10.1016/j.addr.2009.11.018

Hagenaars, N., Mastrobattista, E., Verheul, R. J., Mooren, I., Glansbeek, H. L., Heldens, J. G. M., et al. (2009a). Physicochemical and immunological characterization of $\mathrm{N}, \mathrm{N}, \mathrm{N}$-trimethyl chitosan-coated whole inactivated influenza virus vaccine for intranasal administration. Pharm. Res. 26, 13531364. doi: $10.1007 /$ s1 1095-009-9845-y

Hagenaars, N., Verheul, R. J., Mooren, I., de Jong, P. H., Mastrobattista, E., Glansbeek, H. L., et al. (2009b). Relationship between structure and adjuvanticity of N,N,Ntrimethyl chitosan (TMC) structural variants in a nasal influenza vaccine. J. Control Release 140, 126-133. doi: 10.1016/j.jconrel.2009.08.018

Hasanovic, A., Zehl, M., Reznicek, G., and Valenta, C. (2009). Chitosantripolyphosphate nanoparticles as a possible skin drug delivery system for aciclovir with enhanced stability. J. Pharm. Pharmacol. 61, 1609-1616. doi: 10.1211/jpp.61.12.0004

Hayden, F. (2009). Developing new antiviral agents for influenza treatment: what does the future hold? Clin. Infect. Dis. 48 Suppl 1, S3-13. doi: 10.1086/591851

He, X., Xing, R., Liu, S., Qin, Y., Li, K., Yu, H., et al. (2019). The improved antiviral activities of amino-modified chitosan derivatives on Newcastle virus. Drug Chem. Toxicol., 1-6. doi: 10.1080/01480545.2019.1620264

Hiremath, J., Kang, K.-i., Xia, M., Elaish, M., Binjawadagi, B., Ouyang, K., et al. (2016). Entrapment of H1N1 influenza virus derived conserved peptides in PLGA nanoparticles enhances T cell response and vaccine efficacy in pigs. PloS One 11, e0151922. doi: 10.1371/journal.pone.0151922

$\mathrm{Hu}, \mathrm{L}$., Sun, Y., and Wu, Y. (2013). Advances in chitosan-based drug delivery vehicles. Nanoscale 5, 3103-3111. doi: 10.1039/c3nr00338h

Huang, H. N., Li, T. L., Chan, Y. L., Chen, C. L., and Wu, C. J. (2009). Transdermal immunization with low-pressure-gene-gun mediated chitosan-based DNA vaccines against Japanese encephalitis virus. Biomaterials 30, 6017-6025. doi: 10.1016/j.biomaterials.2009.07.029

Hunsawong, T., Sunintaboon, P., Warit, S., Thaisomboonsuk, B., Jarman, R. G., Yoon, I. K., et al. (2015). Immunogenic Properties of a BCG Adjuvanted Chitosan Nanoparticle-Based Dengue Vaccine in Human Dendritic Cells. PloS Negl. Trop. Dis. 9, e0003958. doi: 10.1371/journal.pntd.0003958

Ilium, L. (1998). Chitosan and its use as a pharmaceutical excipient. Pharm. Res. 15, 1326-1331. doi: 10.1023/A:1011929016601

Illum, L. (2003). Nasal drug delivery-possibilities, problems and solutions. J. Controlled Release 87, 187-198. doi: 10.1016/S0168-3659(02)00363-2

Ingle, A., Gade, A., Pierrat, S., Sonnichsen, C., and Rai, M. (2008). Mycosynthesis of silver nanoparticles using the fungus Fusarium acuminatum and its activity against some human pathogenic bacteria. Curr. Nanosci. 4, 141-144. doi: $10.2174 / 157341308784340804$

Iranpur Mobarakeh, V., Modarressi, M. H., Rahimi, P., Bolhassani, A., Arefian, E., Atyabi, F., et al. (2019). Optimization of chitosan nanoparticles as an anti-HIV siRNA delivery vehicle. Int. J. Biol. Macromol. 129, 305-315. doi: 10.1016/ j.ijbiomac.2019.02.036

Ito, T., Couceiro, J.N. S. S., Kelm, S., Baum, L. G., Krauss, S., Castrucci, M. R., et al. (1998). Molecular basis for the generation in pigs of influenza A viruses with pandemic potential. J. Virol. 72, 7367-7373. doi: 10.1128/JVI.72.9.7367-7373.1998

Jamali, A., Mottaghitalab, F., Abdoli, A., Dinarvand, M., Esmailie, A., Kheiri, M. T., et al. (2018). Inhibiting influenza virus replication and inducing protection against lethal influenza virus challenge through chitosan nanoparticles loaded by siRNA. Drug Delivery Transl. Res. 8, 12-20. doi: 10.1007/s13346-017-0426-z

Jaworska, M. M., Antos, D., and Górak, A. (2020). Review on the application of chitin and chitosan in chromatography. Reactive Funct. Polymers, 104606. doi: 10.1016/j.reactfunctpolym.2020.104606

Je, J.-Y., and Kim, S.-K. (2006). Reactive oxygen species scavenging activity of aminoderivatized chitosan with different degree of deacetylation. Bioorg. medicinal Chem. 14, 5989-5994. doi: 10.1016/j.bmc.2006.05.016

Jiang, L., Qian, F., He, X., Wang, F., Ren, D., He, Y., et al. (2007). Novel chitosan derivative nanoparticles enhance the immunogenicity of a DNA vaccine encoding hepatitis B virus core antigen in mice. J. Gene Med. 9, 253-264. doi: $10.1002 /$ jgm.1017

Jin, Z., Li, D., Dai, C., Cheng, G., Wang, X., and Zhao, K. (2017). Response of live Newcastle disease virus encapsulated in N-2-hydroxypropyl dimethylethyl ammonium chloride chitosan nanoparticles. Carbohydr. Polym. 171, 267280. doi: $10.1016 /$ j.carbpol.2017.05.022

Jonassen, H., Kjøniksen, A.-L., and Hiorth, M. (2012). Stability of chitosan nanoparticles cross-linked with tripolyphosphate. Biomacromolecules 13, 3747-3756. doi: 10.1021/bm301207a

Kabanov, A. V., Bronich, T. K., Kabanov, V. A., Yu, K., and Eisenberg, A. (1996). Soluble stoichiometric complexes from poly (N-ethyl-4-vinylpyridinium) cations and poly (ethylene oxide)-block-polymethacrylate anions. Macromolecules 29, 6797-6802. doi: 10.1021/ma960120k

Kang, M. L., Cho, C. S., and Yoo, H. S. (2009). Application of chitosan microspheres for nasal delivery of vaccines. Biotechnol. Adv. 27, 857-865. doi: 10.1016/j.biotechadv.2009.06.007

Kato, Y., Onishi, H., and Machida, Y. (2001). Biological characteristics of lactosaminated $\mathrm{N}$-succinyl-chitosan as a liver-specific drug carrier in mice. J. Controlled Release 70, 295-307. doi: 10.1016/S0168-3659(00)00356-4

Kavaliauskis, A., Arnemo, M., Speth, M., Lagos, L., Rishovd, A. L., Estepa, A., et al. (2016). Protective effect of a recombinant VHSV-G vaccine using poly(I:C) loaded nanoparticles as an adjuvant in zebrafish (Danio rerio) infection model. Dev. Comp. Immunol. 61, 248-257. doi: 10.1016/j.dci.2016.04.010

Khatri, K., Goyal, A. K., Gupta, P. N., Mishra, N., Mehta, A., and Vyas, S. P. (2008a). Surface modified liposomes for nasal delivery of DNA vaccine. Vaccine 26, 2225-2233. doi: 10.1016/j.vaccine.2008.02.058

Khatri, K., Goyal, A. K., Gupta, P. N., Mishra, N., and Vyas, S. P. (2008b). Plasmid DNA loaded chitosan nanoparticles for nasal mucosal immunization against hepatitis B. Int. J. Pharm. 354, 235-241. doi: 10.1016/j.jpharm.2007.11.027

Khimmakthong, U., Kongmee, P., Deachamag, P., Leggat, U., and Chotigeat, W. (2013). Activation of an immune response in Litopenaeus vannamei by oral immunization with phagocytosis activating protein (PAP) DNA. Fish Shellfish Immunol. 34, 929-938. doi: 10.1016/j.fsi.2013.01.004

Kim, A. E., Dintaman, J. M., Waddell, D. S., and Silverman, J. A. (1998). Saquinavir, an HIV protease inhibitor, is transported by P-glycoprotein. J. Pharmacol. Exp. Ther. 286, 1439-1445.

Kim, R. B., Fromm, M. F., Wandel, C., Leake, B., Wood, A. J., Roden, D. M., et al. (1998). The drug transporter P-glycoprotein limits oral absorption and brain entry of HIV-1 protease inhibitors. J. Clin. Invest. 101, 289-294. doi: 10.1172/JCI1269

Kim, S.-K. (2013). Marine biomaterials: characterization, isolation and applications (CRC press).

Kim, S.-H., and Jang, Y.-S. (2017). The development of mucosal vaccines for both mucosal and systemic immune induction and the roles played by adjuvants. Clin. Exp. Vaccine Res. 6, 15-21. doi: 10.7774/cevr.2017.6.1.15

Kim, B. G., and Kang, I. J. (2008). Evaluation of the effects of biodegradable nanoparticles on a vaccine delivery system using AFM, SEM, and TEM. Ultramicroscopy 108, 1168-1173. doi: 10.1016/j.ultramic.2008.04.038

Klaykruayat, B., Siralertmukul, K., and Srikulkit, K. (2010). Chemical modification of chitosan with cationic hyperbranched dendritic polyamidoamine and its antimicrobial activity on cotton fabric. Carbohydr. Polymers 80, 197-207. doi: 10.1016/j.carbpol.2009.11.013

Kmiec, M., Pighinelli, L., Tedesco, M. F., Silva, M. M., and Reis, V. (2017). Chitosan-properties and applications in dentistry. Adv. Tissue Eng. Regener. Med. Open Access 2, 00035.

Kole, R., Krainer, A. R., and Altman, S. (2012). RNA therapeutics: beyond RNA interference and antisense oligonucleotides. Nat. Rev. Drug Discovery 11, 125140. doi: $10.1038 / \mathrm{nrd} 3625$

Kole, S., Qadiri, S. S. N., Shin, S. M., Kim, W. S., Lee, J., and Jung, S. J. (2019). Nanoencapsulation of inactivated-viral vaccine using chitosan nanoparticles: Evaluation of its protective efficacy and immune modulatory effects in olive flounder (Paralichthys olivaceus) against viral haemorrhagic septicaemia virus (VHSV) infection. Fish Shellfish Immunol. 91, 136-147. doi: 10.1016/ j.fsi.2019.05.017

Kulikov, S. N., Chirkov, S. N., Il'ina, A. V., Lopatin, S. A., and Varlamov, V. P. (2006). Effect of the molecular weight of chitosan on its antiviral activity in plants. Appl. Biochem. Microbiol. 42, 200-203. doi: 10.1134/S0003683806020165

Kumar, M. N., Muzzarelli, R. A., Muzzarelli, C., Sashiwa, H., and Domb, A. J. (2004). Chitosan chemistry and pharmaceutical perspectives. Chem. Rev. 104, 6017-6084. doi: 10.1021/cr030441b

Kumar, A., Ma, H., Zhang, X., Huang, K., Jin, S., Liu, J., et al. (2012). Gold nanoparticles functionalized with therapeutic and targeted peptides for cancer treatment. Biomaterials 33, 1180-1189. doi: 10.1016/j.biomaterials.2011.10.058 
Kwon, S. Y., and Lee, C. H. (2011). Epidemiology and prevention of hepatitis B virus infection. Korean J. Hepatol. 17, 87. doi: 10.3350/kjhep.2011.17.2.87

Kyd, J. M., Ruth Foxwell, A., and Cripps, A. W. (2001). Mucosal immunity in the lung and upper airway. Vaccine 19, 2527-2533. doi: 10.1016/S0264-410X(00)00484-9

Langer, R. (1998). Drug delivery and targeting. Nature 392, 5-10.

Lara, H. H., Ayala-Nuñez, N. V., Ixtepan-Turrent, L., and Rodriguez-Padilla, C. (2010). Mode of antiviral action of silver nanoparticles against HIV-1. J. Nanobiotechnol. 8, 1. doi: 10.1186/1477-3155-8-1

Lavelle, E. C., Grant, G., Pfuller, U., and O’Hagan, D. T. (2004). Immunological implications of the use of plant lectins for drug and vaccine targeting to the gastrointestinal tract. J. Drug Targeting 12, 89-95. doi: 10.1080/106118604 10001693733

Le Cleach, L., Trinquart, L., Do, G., Maruani, A., Lebrun-Vignes, B., Ravaud, P., et al. (2014). Oral antiviral therapy for prevention of genital herpes outbreaks in immunocompetent and nonpregnant patients. Cochrane Database System. Rev. 3 (8), CD009036.

Lee, J., Kim, Y. M., Kim, J. H., Cho, C. W., Jeon, J. W., Park, J. K., et al. (2018). Nasal delivery of chitosan/alginate nanoparticle encapsulated bee (Apis mellifera) venom promotes antibody production and viral clearance during porcine reproductive and respiratory syndrome virus infection by modulating T cell related responses. Vet. Immunol. Immunopathol. 200, 40-51. doi: 10.1016/j.vetimm.2018.04.006

Lembo, D., Donalisio, M., Rusnati, M., Bugatti, A., Cornaglia, M., Cappello, P., et al. (2008). Sulfated K5 Escherichia coli polysaccharide derivatives as widerange inhibitors of genital types of human papillomavirus. Antimicrob. Agents Chemother. 52, 1374-1381. doi: 10.1128/AAC.01467-07

Li, Q., Du, Y.-Z., Yuan, H., Zhang, X.-G., Miao, J., Cui, F.-D., et al. (2010). Synthesis of lamivudine stearate and antiviral activity of stearic acid-g-chitosan oligosaccharide polymeric micelles delivery system. Eur. J. Pharm. Sci. 41, 498507. doi: 10.1016/j.ejps.2010.08.004

Li, X., Wu, P., Gao, G. F., and Cheng, S. (2011). Carbohydrate-functionalized chitosan fiber for influenza virus capture. Biomacromolecules 12, 3962-3969. doi: $10.1021 / \mathrm{bm} 200970 \mathrm{x}$

Li, X., and Chan, W. K. (1999). Transport, metabolism and elimination mechanisms of anti-HIV agents. Advanced Drug Delivery Rev. 39, 81-103. doi: 10.1016/S0169-409X(99)00021-6

Lin, A., Liu, Y., Huang, Y., Sun, J., Wu, Z., Zhang, X., et al. (2008). Glycyrrhizin surface-modified chitosan nanoparticles for hepatocyte-targeted delivery. Int. J. Pharmaceutics 359, 247-253. doi: 10.1016/j.ijpharm.2008.03.039

Little, S. J., Holte, S., Routy, J.-P., Daar, E. S., Markowitz, M., Collier, A. C., et al. (2002). Antiretroviral-drug resistance among patients recently infected with HIV. New Engl. J. Med. 347, 385-394. doi: 10.1056/NEJMoa013552

Liu, Q., Zheng, X., Zhang, C., Shao, X., Zhang, X., Zhang, Q., et al. (2015). Conjugating influenza a (H1N1) antigen to $n$-trimethylaminoethylmethacrylate chitosan nanoparticles improves the immunogenicity of the antigen after nasal administration. J. Med. Virol. 87, 1807-1815. doi: 10.1002/jmv.24253

Lockhat, H. A., Silva, J. R. A., Alves, C. N., Govender, T., Lameira, J., Maguire, G. E. M., et al. (2016). Binding free energy calculations of nine FDA-approved protease inhibitors against HIV-1 subtype C I36T $\uparrow \mathrm{T}$ containing 100 amino acids per monomer. Chem. Biol. Drug design 87, 487-498. doi: 10.1111/cbdd.12690

Lopes, P. D., Okino, C. H., Fernando, F. S., Pavani, C., Casagrande, V. M., Lopez, R. F. V., et al. (2018). Inactivated infectious bronchitis virus vaccine encapsulated in chitosan nanoparticles induces mucosal immune responses and effective protection against challenge. Vaccine 36, 2630-2636. doi: 10.1016/ j.vaccine.2018.03.065

Louw, A. M., Kolar, M. K., Novikova, L. N., Kingham, P. J., Wiberg, M., Kjems, J., et al. (2016). Chitosan polyplex mediated delivery of miRNA-124 reduces activation of microglial cells in vitro and in rat models of spinal cord injury. Nanomedicine 12, 643-653. doi: 10.1016/j.nano.2015.10.011

Lugade, A. A., Bharali, D. J., Pradhan, V., Elkin, G., Mousa, S. A., and Thanavala, Y. (2013). Single low-dose un-adjuvanted HBsAg nanoparticle vaccine elicits robust, durable immunity. Nanomedicine 9, 923-934. doi: 10.1016/j.nano.2013.03.008

Luo, Y., and Wang, Q. (2014). Recent development of chitosan-based polyelectrolyte complexes with natural polysaccharides for drug delivery. Int. J. Biol. Macromol. 64, 353-367. doi: 10.1016/j.ijbiomac.2013.12.017

Maitra, A., Ghosh, P. K., De, T. K., and Sahoo, S. K. (1999). "Process for the preparation of highly monodispersed polymeric hydrophilic nanoparticles," in Google Patents.
Mallipeddi, R., and Rohan, L. C. (2010). Progress in antiretroviral drug delivery using nanotechnology. Int. J. Nanomed. 5, 533-547.

Maseko, S. B., Natarajan, S., Sharma, V., Bhattacharyya, N., Govender, T., and Sayed, Y. (2016). Purification and characterization of naturally occurring HIV-1 (South African subtype C) protease mutants from inclusion bodies. Protein Expression Purification 122, 90-96. doi: 10.1016/j.pep.2016.02.013

McKiernan, P. J., and Greene, C. M. (2015). MicroRNA Dysregulation in Cystic Fibrosis. Mediators Inflammation 2015, 529642.

McNeil, S. E. (2011). Unique benefits of nanotechnology to drug delivery and diagnostics. Methods Mol. Biol. 697, 3-8. doi: 10.1007/978-1-60327-198-1_1

Medepalli, K. K. (2008). Advanced nanomaterials for biomedical applications (University of Louisville).

Mehendale, R., Joshi, M., and Patravale, V. B. (2013). Nanomedicines for treatment of viral diseases. Crit. Rev. Ther. Drug Carrier Syst. 30, 1-49. doi: 10.1615/CritRevTherDrugCarrierSyst.2013005469

Meng, X., Xing, R., Liu, S., Yu, H., Li, K., Qin, Y., et al. (2012). Molecular weight and $\mathrm{pH}$ effects of aminoethyl modified chitosan on antibacterial activity in vitro. Int. J. Biol. Macromol. 50, 918-924. doi: 10.1016/j.ijbiomac.2012.01.018

Meng, J., Zhang, T., Agrahari, V., Ezoulin, M. J., and Youan, B. B. (2014). Comparative biophysical properties of tenofovir-loaded, thiolated and nonthiolated chitosan nanoparticles intended for HIV prevention. Nanomed. (Lond) 9, 1595-1612. doi: 10.2217/nnm.13.136

Mishra, N., Khatri, K., Gupta, M., and Vyas, S. P. (2014). Development and characterization of LTA-appended chitosan nanoparticles for mucosal immunization against hepatitis B. Artif. Cells Nanomed. Biotechnol. 42, 245 255. doi: $10.3109 / 21691401.2013 .809726$

Mohamed, S. H., Arafa, A. S., Mady, W. H., Fahmy, H. A., Omer, L. M., and Morsi, R. E. (2018). Preparation and immunological evaluation of inactivated avian influenza virus vaccine encapsulated in chitosan nanoparticles. Biologicals 51, 46-53. doi: 10.1016/j.biologicals.2017.10.004

Mohammed, M. A., Syeda, J., Wasan, K. M., and Wasan, E. K. (2017). An overview of chitosan nanoparticles and its application in non-parenteral drug delivery. Pharmaceutics 9, 53. doi: 10.3390/pharmaceutics 9040053

Moon, H. J., Lee, J. S., Talactac, M. R., Chowdhury, M. Y., Kim, J. H., Park, M. E., et al. (2012). Mucosal immunization with recombinant influenza hemagglutinin protein and poly gamma-glutamate/chitosan nanoparticles induces protection against highly pathogenic influenza A virus. Vet. Microbiol. 160, 277-289. doi: 10.1016/j.vetmic.2012.05.035

Moreno, P. M., and Pêgo, A. P. (2014). Therapeutic antisense oligonucleotides against cancer: hurdling to the clinic. Front. Chem. 2, 87. doi: 10.3389/ fchem.2014.00087

Muthu, M. S., and Singh, S. (2009). Targeted nanomedicines: effective treatment modalities for cancer, AIDS and brain disorders. Nanomed. (Lond) 4, 105-118. doi: $10.2217 / 17435889.4 .1 .105$

Muzzarelli, R. A. A., Jeuniaux, C., and Gooday, G. W. (1986). Chitin in nature and technology (Springer).

Muzzarelli, R. A. A., Mattioli-Belmonte, M., and Muzzarelli, B. (1998). Advances in Chitin. SciLyon: Andru 2, 219-224.

Nagpal, K., Singh, S. K., and Mishra, D. N. (2010). Chitosan nanoparticles: a promising system in novel drug delivery. Chem. Pharm. Bull. 58, 1423-1430. doi: $10.1248 / \mathrm{cpb} .58 .1423$

Nahand, J. S., Jamshidi, S., Hamblin, M. R., Mahjoubin-Tehran, M., Vosough, M., Jamali, M., et al. (2020a). Circular RNAs: New Epigenetic Signatures in Viral Infections. Front. Microbiol. 11, 1853. doi: 10.3389/fmicb.2020.01853

Nahand, J. S., Mahjoubin-Tehran, M., Moghoofei, M., Pourhanifeh, M. H., Mirzaei, H. R., Asemi, Z., et al. (2020b). Exosomal miRNAs: novel players in viral infection. Epigenomics 12, 353-370. doi: 10.2217/epi-2019-0192

Nalwa, H. S. (1999). Handbook of nanostructured materials and nanotechnology, five-volume set (Academic Press).

Nanda, R. K., Hajam, I. A., Edao, B. M., Ramya, K., Rajangam, M., Chandra Sekar, S., et al. (2014). Immunological evaluation of mannosylated chitosan nanoparticles based foot and mouth disease virus DNA vaccine, pVAC FMDV VP1-OmpA in guinea pigs. Biologicals 42, 153-159. doi: 10.1016/j.biologicals.2014.01.002

Nasrollahzadeh, M., Shafiei, N., Nezafat, Z., Bidgoli, N. S. S., and Soleimani, F. (2020). Recent progresses in the application of cellulose, starch, alginate, gum, pectin, chitin and chitosan based (nano) catalysts in sustainable and selective oxidation reactions: A review. Carbohydr. Polymers, 116353. doi: 10.1016/ j.carbpol.2020.116353 
Neutra, M. R., and Kozlowski, P. A. (2006). Mucosal vaccines: the promise and the challenge. Nat. Rev. Immunol. 6, 148-158. doi: 10.1038/nril777

Ng, J. C. Y., Cheung, W. H., and McKay, G. (2002). Equilibrium studies of the sorption of $\mathrm{Cu}$ (II) ions onto chitosan. J. Colloid Interface Sci. 255, 64-74. doi: 10.1006/jcis.2002.8664

Ngo, D.-H., Vo, T.-S., Ngo, D.-N., Kang, K.-H., Je, J.-Y., Pham, H. N.-D., et al. (2015). Biological effects of chitosan and its derivatives. Food Hydrocolloids 51, 200-216. doi: 10.1016/j.foodhyd.2015.05.023

Niemeyer, C. M. (2006). Nanobiotechnology. Rev. Cell Biol. Mol. Med.

Nishiyama, N., Kato, Y., Sugiyama, Y., and Kataoka, K. (2001). Cisplatin-loaded polymer-metal complex micelle with time-modulated decaying property as a novel drug delivery system. Pharm. Res. 18, 1035-1041. doi: 10.1023/ A:1010908916184

Niwa, T., Takeuchi, H., Hino, T., Kunou, N., and Kawashima, Y. (1993). Preparations of biodegradable nanospheres of water-soluble and insoluble drugs with D, L-lactide/glycolide copolymer by a novel spontaneous emulsification solvent diffusion method and the drug release behavior. J. Controlled Release 25, 89-98. doi: 10.1016/0168-3659(93)90097-O

Nugent, J. (1998). The design and delivery of non-parenteral vaccines.

Pan, L., Zhang, Z., Lv, J., Zhou, P., Hu, W., Fang, Y., et al. (2014). Induction of mucosal immune responses and protection of cattle against direct-contact challenge by intranasal delivery with foot-and-mouth disease virus antigen mediated by nanoparticles. Int. J. Nanomed. 9, 5603-5618. doi: 10.2147/IJN.S72318

Panácek, A., Kolár, M., Vecerová, R., Prucek, R., Soukupová, J., Krystof, V., et al. (2009). Antifungal activity of silver nanoparticles against Candida spp. Biomaterials 30, 6333-6340. doi: 10.1016/j.biomaterials.2009.07.065

Parboosing, R., Maguire, G. E., Govender, P., and Kruger, H. G. (2012). Nanotechnology and the treatment of HIV infection. Viruses 4, 488-520. doi: 10.3390/v4040488

Pathinayake, P. S., Gayan Chathuranga, W. A., Lee, H. C., Chowdhury, M. Y. E., Sung, M. H., Lee, J. S., et al. (2018). Inactivated enterovirus 71 with poly- $\gamma$ glutamic acid/Chitosan nano particles (PC NPs) induces high cellular and humoral immune responses in BALB/c mice. Arch. Virol. 163, 2073-2083. doi: 10.1007/s00705-018-3837-3

Pawar, R., Jadhav, W., Bhusare, S., Borade, R., Farber, S., Itzkowitz, D., et al. (2008). "Polysaccharides as carriers of bioactive agents for medical applications," in Natural-based polymers for biomedical applications (Elsevier).

Peter, M. G. (1995). Applications and environmental aspects of chitin and chitosan. J. Macromol. Sci. Part A: Pure Appl. Chem. 32, 629-640.

Petros, R. A., and DeSimone, J. M. (2010). Strategies in the design of nanoparticles for therapeutic applications. Nat. Rev. Drug Discovery 9, 615-627. doi: 10.1038/ $\operatorname{nrd} 2591$

Pillai, C. K. S., Paul, W., and Sharma, C. P. (2009). Chitin and chitosan polymers: Chemistry, solubility and fiber formation. Prog. Polymer Sci. 34, 641-678. doi: 10.1016/j.progpolymsci.2009.04.001

Poo, H., Park, C., Kwak, M.-S., Choi, D.-Y., Hong, S.-P., Lee, I.-H., et al. (2010). New Biological Functions and Applications of High-Molecular-Mass Poly- $\gamma$ glutamic Acid. Chem. Biodiversity 7, 1555-1562. doi: 10.1002/cbdv.200900283

Pospieszny, H., Chirkov, S., and Atabekov, J. (1991). Induction of antiviral resistance in plants by chitosan. Plant Sci. 79, 63-68. doi: 10.1016/0168-9452 (91)90070-O

Prabhu, P., Patravale, V., and Joshi, M. (2012). Nanocarriers for effective topical delivery of anti-infectives. Curr. Nanosci. 8, 491-503. doi: 10.2174/ 157341312801784221

Qasim, M., Lim, D. J., Park, H., and Na, D. (2014). Nanotechnology for diagnosis and treatment of infectious diseases. J. Nanosci. Nanotechnol. 14, 7374-7387. doi: 10.1166/jnn.2014.9578

Qi, M., Zhang, X.-E., Sun, X., Zhang, X., Yao, Y., Liu, S., et al. (2018). Intranasal nanovaccine confers homo-and hetero-subtypic influenza protection. Small 14, 1703207.

Radhakumary, C., Antonty, M., and Sreenivasan, K. (2011). Drug loaded thermoresponsive and cytocompatible chitosan based hydrogel as a potential wound dressing. Carbohydr. Polymers 83, 705-713. doi: 10.1016/j.carbpol. 2010.08.042

Ragelle, H., Vandermeulen, G., and Préat, V. (2013). Chitosan-based siRNA delivery systems. J. Control Release 172, 207-218. doi: 10.1016/j.jconrel. 2013.08.005
Ramana, L. N., Sharma, S., Sethuraman, S., Ranga, U., and Krishnan, U. M. (2014). Evaluation of chitosan nanoformulations as potent anti-HIV therapeutic systems. Biochim. Biophys. Acta 1840, 476-484. doi: 10.1016/j.bbagen. 2013.10.002

Rani, D., Saxena, R., Nayak, B., and Srivastava, S. (2018). Cloning and expression of truncated ORF2 as a vaccine candidate against hepatitis E virus 8 (10), 414. doi: 10.1007/s13205-018-1437-2

Rashki, S., Asgarpour, K., Tarrahimofrad, H., Hashemipour, M., Ebrahimi, M. S., Fathizadeh, H., et al. (2020). Chitosan-Based Nanoparticles against bacterial infections. Carbohydr. Polymers, 117108.

Rashki, S., Asgarpour, K., Tarrahimofrad, H., Hashemipour, M., Ebrahimi, M. S., Fathizadeh, H., et al. (2021). Chitosan-based nanoparticles against bacterial infections. Carbohydr. Polym. 251, 117108. doi: 10.1016/j.carbpol.2020.117108

Roizman, B. (2006). Herpes simplex virus. Fields Virol., 2501-2601.

ROUGET, C. (1859). Des substances anlylacees duns Ie tissu des aninltUIX specialenlcnt [esurticules (Chitine). ()nlptes Rendus 48t, 792-795.

Sadati, S. F., Jamali, A., Abdoli, A., Abedi-Valugerdi, M., Gholami, S., Alipour, S., et al. (2018). Simultaneous formulation of influenza vaccine and chitosan nanoparticles within $\mathrm{CpG}$ oligodesoxi nucleotides leads to dose-sparing and protects against lethal challenge in the mouse model. Pathog. Dis. 76. doi: $10.1093 /$ femspd/fty070

Sadri Nahand, J., Bokharaei-Salim, F., Karimzadeh, M., Moghoofei, M., Karampoor, S., Mirzaei, H. R., et al. (2020). MicroRNAs and exosomes: key players in HIV pathogenesis. HIV Med. 21, 246-278. doi: 10.1111/hiv.12822

Saikia, C., Gogoi, P., and Maji, T. K. (2015). Chitosan: A promising biopolymer in drug delivery applications. J. Mol. Genet. Med. S 4. doi: 10.4172/1747-0862.S4-006

Santos-Carballal, B., Fernández Fernández, E., and Goycoolea, F. M. (2018). Chitosan in Non-Viral Gene Delivery: Role of Structure, Characterization Methods, and Insights in Cancer and Rare Diseases Therapies. Polymers (Basel) 10. doi: 10.3390/polym10040444

Santos-Martinez, M. J., Rahme, K., Corbalan, J. J., Faulkner, C., Holmes, J. D., Tajber, L., et al. (2014). Pegylation increases platelet biocompatibility of gold nanoparticles. J. BioMed. Nanotechnol. 10, 1004-1015. doi: 10.1166/jbn.2014.1813

Sanvicens, N., and Marco, M. P. (2008). Multifunctional nanoparticles-properties and prospects for their use in human medicine. Trends Biotechnol. 26, 425433. doi: $10.1016 /$ j.tibtech.2008.04.005

Sawaengsak, C., Mori, Y., Yamanishi, K., Mitrevej, A., and Sinchaipanid, N. (2014). Chitosan nanoparticle encapsulated hemagglutinin-split influenza virus mucosal vaccine. AAPS PharmSciTech 15, 317-325. doi: 10.1208/ s12249-013-0058-7

Schapiro, J. M., Winters, M. A., Stewart, F., Efron, B., Norris, J., Kozal, M. J., et al. (1996). The effect of high-dose saquinavir on viral load and CD4+ T-cell counts in HIV-infected patients. Ann. Internal Med. 124, 1039-1050. doi: 10.7326/ 0003-4819-124-12-199606150-00003

Scheller, F. W., Bier, F. F., and Pfeiffer, D. (1995). Biosensoren: grundlagen und anwendungen. tm-Technisches Messen 62, 213-219. doi: 10.1524/teme. 1995.62.jg. 213

Schütz, C. A., Juillerat-Jeanneret, L., Mueller, H., Lynch, I., and Riediker, M. (2013). Therapeutic nanoparticles in clinics and under clinical evaluation. Nanomed. (Lond) 8, 449-467. doi: 10.2217/nnm.13.8

Serrano-Sevilla, I., Artiga, Á., Mitchell, S. G., De Matteis, L., and de la Fuente, J. M. (2019). Natural Polysaccharides for siRNA Delivery: Nanocarriers Based on Chitosan, Hyaluronic Acid, and Their Derivatives. Molecules 24. doi: 10.3390/ molecules 24142570

Shafer, R. W., Rhee, S.-Y., Pillay, D., Miller, V., Sandstrom, P., Schapiro, J. M., et al. (2007). HIV-1 protease and reverse transcriptase mutations for drug resistance surveillance. AIDS (London England) 21, 215. doi: 10.1097/QAD. 0b013e328011e691

Shafti-Keramat, S., Handisurya, A., Kriehuber, E., Meneguzzi, G., Slupetzky, K., and Kirnbauer, R. (2003). Different heparan sulfate proteoglycans serve as cellular receptors for human papillomaviruses. J. Virol. 77, 13125-13135. doi: 10.1128/JVI.77.24.13125-13135.2003

Sharma, V. K., Sharma, R. K., and Singh, S. K. (2014). Antisense oligonucleotides: modifications and clinical trials. MedChemComm 5, 1454-1471. doi: 10.1039/ C4MD00184B

Shibata, Y., Foster, L.A., Metzger, W.J., and Myrvik, Q. N. (1997). Alveolar macrophage priming by intravenous administration of chitin particles, 
polymers of N-acetyl-D-glucosamine, in mice. Infect. Immun. 65, 1734-1741. doi: 10.1128/IAI.65.5.1734-1741.1997

Singh, P., Prabakaran, D., Jain, S., Mishra, V., Jaganathan, K. S., and Vyas, S. P. (2004). Cholera toxin B subunit conjugated bile salt stabilized vesicles (bilosomes) for oral immunization. Int. J. Pharmaceutics 278, 379-390. doi: 10.1016/j.ijpharm.2004.03.014

Singh, B., Choi, Y. J., Park, I. K., Akaike, T., and Cho, C. S. (2014). Chemical modification of chitosan with $\mathrm{pH}$-sensitive molecules and specific ligands for efficient DNA transfection and siRNA silencing. J. Nanosci. Nanotechnol. 14, 564-576. doi: 10.1166/jnn.2014.9079

Singh, R. P., Gangadharappa, H. V., and Mruthunjaya, K. (2018). Phytosome complexed with chitosan for gingerol delivery in the treatment of respiratory infection: In vitro and in vivo evaluation. Eur. J. Pharm. Sci. 122, 214-229. doi: 10.1016/j.ejps.2018.06.028

Slütter, B., Bal, S. M., Que, I., Kaijzel, E., Loüwik, C., Bouwstra, J., et al. (2010). Antigen- adjuvant nanoconjugates for nasal vaccination: an improvement over the use of nanoparticles? Mol. Pharmaceutics 7, 2207-2215. doi: 10.1021/ mp100210g

Spruance, S. L., and Kriesel, J. D. (2002). Treatment of herpes simplex labialis. Herpes: J. IHMF 9, 64-69.

Su, X., Zivanovic, S., and D'SOUZA, DORIS H (2009). Effect of chitosan on the infectivity of murine norovirus, feline calicivirus, and bacteriophage MS2. J. Food Prot. 72, 2623-2628. doi: 10.4315/0362-028X-72.12.2623

Subbiah, R., Ramalingam, P., Ramasundaram, S., Kim, D. Y., Park, K., Ramasamy, M. K., et al. (2012). N,N,N-Trimethyl chitosan nanoparticles for controlled intranasal delivery of HBV surface antigen. Carbohydr. Polym. 89, 1289-1297. doi: 10.1016/j.carbpol.2012.04.056

Sun, R. W., Chen, R., Chung, N. P., Ho, C. M., Lin, C. L., and Che, C. M. (2005). Silver nanoparticles fabricated in Hepes buffer exhibit cytoprotective activities toward HIV-1 infected cells. Chem. Commun. (Camb.), 5059-5061. doi: $10.1039 / \mathrm{b} 510984 \mathrm{a}$

Tahamtan, A., Barati, M., Tabarraei, A., Mohebbi, S. R., Shirian, S., Gorji, A., et al. (2018). Antitumor Immunity Induced by Genetic Immunization with Chitosan Nanoparticle Formulated Adjuvanted for HPV-16 E7 DNA Vaccine. Iran J. Immunol. 15, 269-280.

Taju, G., Kumar, D. V., Majeed, S. A., Vimal, S., Tamizhvanan, S., Kumar, S. S., et al. (2018). Delivery of viral recombinant VP28 protein using chitosan tripolyphosphate nanoparticles to protect the whiteleg shrimp, Litopenaeus vannamei from white spot syndrome virus infection. Int. J. Biol. Macromol. 107, 1131-1141. doi: 10.1016/j.ijbiomac.2017.09.094

Tamura, S.-i., and Kurata, T. (2004). Defense mechanisms against influenza virus infection in the respiratory tract mucosa. Jpn. J. Infect. Dis. 57, 236-247.

Tang, R., Zhai, Y., Dong, L., Malla, T., and Hu, K. (2018). Immunization with dendritic cell-based DNA vaccine pRSC-NLDC145.gD-IL21 protects mice against herpes simplex virus keratitis. Immunotherapy 10, 189-200. doi: 10.2217/imt-2017-0060

Tao, F., Cheng, Y., Shi, X., Zheng, H., Du, Y., and Deng, H. (2020). Applications of chitin and chitosan nanofibers in bone regenerative engineering. Carbohydr. Polymers 230, 115658. doi: 10.1016/j.carbpol.2019.115658

Taranejoo, S., Janmaleki, M., Rafienia, M., Kamali, M., and Mansouri, M. (2011). Chitosan microparticles loaded with exotoxin A subunit antigen for intranasal vaccination against Pseudomonas aeruginosa: An in vitro study. Carbohydr. Polymers 83, 1854-1861. doi: 10.1016/j.carbpol.2010.10.051

Theerawanitchpan, G., Saengkrit, N., Sajomsang, W., Gonil, P., Ruktanonchai, U., Saesoo, S., et al. (2012). Chitosan and its quaternized derivative as effective long dsRNA carriers targeting shrimp virus in Spodoptera frugiperda 9 cells. J. Biotechnol. 160, 97-104. doi: 10.1016/j.jbiotec.2012.04.011

Thomas, C., Rawat, A., Hope-Weeks, L., and Ahsan, F. (2011). Aerosolized PLA and PLGA nanoparticles enhance humoral, mucosal and cytokine responses to hepatitis B vaccine. Mol. Pharmaceutics 8, 405-415. doi: 10.1021/mp100255c

Thummel, K. E., Kunze, K. L., and Shen, D. D. (1997). Enzyme-catalyzed processes of first-pass hepatic and intestinal drug extraction. Advanced Drug Delivery Rev. 27, 99-127. doi: 10.1016/S0169-409X(97)00039-2

Timur, S. S., Şahin, A., Aytekin, E., Öztürk, N., Polat, K. H., Tezel, N., et al. (2018). Design and in vitro evaluation of tenofovir-loaded vaginal gels for the prevention of HIV infections. Pharm. Dev. Technol. 23, 301-310. doi: $10.1080 / 10837450.2017 .1329835$
Tong, J., and Chen, L. (2013). Preparation and application of magnetic chitosan derivatives in separation processes. Anal. Lett. 46, 2635-2656. doi: 10.1080/ 00032719.2013.807815

Torchilin, V. P. (2008). Tat peptide-mediated intracellular delivery of pharmaceutical nanocarriers. Advanced Drug Delivery Rev. 60, 548-558. doi: 10.1016/j.addr.2007.10.008

Tritch, R. J., Cheng, Y. E., Yin, F. H., and Erickson-Viitanen, S. (1991). Mutagenesis of protease cleavage sites in the human immunodeficiency virus type 1 gag polyprotein. J. Virol. 65, 922-930. doi: 10.1128/JVI.65.2.922930.1991

Tsai, W.-B., Chen, Y.-R., Liu, H.-L., and Lai, J.-Y. (2011). Fabrication of UVcrosslinked chitosan scaffolds with conjugation of RGD peptides for bone tissue engineering. Carbohydr. Polymers 85, 129-137. doi: 10.1016/j.carbpol.2011.02.003

Uto, T., Wang, X., Sato, K., Haraguchi, M., Akagi, T., Akashi, M., et al. (2007). Targeting of antigen to dendritic cells with poly $(\gamma$-glutamic acid) nanoparticles induces antigen-specific humoral and cellular immunity. J. Immunol. 178, 2979-2986. doi: 10.4049/jimmunol.178.5.2979

Van Der Lubben, I. M., Konings, F. A. J., Borchard, G., Verhoef, J. C., and Junginger, H. E. (2001a). In vivo uptake of chitosan microparticles by murine Peyer's patches: visualization studies using confocal laser scanning microscopy and immunohistochemistry. J. Drug Targeting 9, 39-47. doi: 10.3109/ 10611860108995631

Van der Lubben, I. M., Verhoef, J. C., Borchard, G., and Junginger, H. E. (2001b). Chitosan for mucosal vaccination. Advanced Drug Delivery Rev. 52, 139-144. doi: 10.1016/S0169-409X(01)00197-1

Van der Lubben, I. M., Verhoef, J. C., Van Aelst, A. C., Borchard, G., and Junginger, H. E. (2001c). Chitosan microparticles for oral vaccination:: preparation, characterization and preliminary in vivo uptake studies in murine Peyer's patches. Biomaterials 22, 687-694. doi: 10.1016/S0142-9612 (00)00231-3

van Ginkel, F. W., Jackson, R. J., Yuki, Y., and McGhee, J. R. (2000). Cutting edge: the mucosal adjuvant cholera toxin redirects vaccine proteins into olfactory tissues. J. Immunol. 165, 4778-4782. doi: 10.4049/jimmunol.165.9.4778

Van Reeth, K., and Ma, W. (2012). "Swine influenza virus vaccines: to change or not to change-that's the question," in Swine Influenza (Springer).

van Riet, E., Ainai, A., Suzuki, T., and Hasegawa, H. (2012). Mucosal IgA responses in influenza virus infections; thoughts for vaccine design. Vaccine 30, 5893-5900. doi: 10.1016/j.vaccine.2012.04.109

Varma, A. J., Deshpande, S. V., and Kennedy, J. F. (2004). Metal complexation by chitosan and its derivatives: a review. Carbohydr. Polymers 55, 77-93. doi: 10.1016/j.carbpol.2003.08.005

Vicente, S., Peleteiro, M., Díaz-Freitas, B., Sanchez, A., González-Fernández, Á., and Alonso, M. J. (2013). Co-delivery of viral proteins and a TLR7 agonist from polysaccharide nanocapsules: a needle-free vaccination strategy. J. Control Release 172, 773-781. doi: 10.1016/j.jconrel.2013.09.012

Vincent, A. L., Ma, W., Lager, K. M., Janke, B. H., and Richt, J. A. (2008). Swine influenza viruses: a North American perspective. Adv. Virus Res. 72, 127-154. doi: 10.1016/S0065-3527(08)00403-X

Vincent, A. L., Perez, D. R., Rajao, D., Anderson, T. K., Abente, E. J., Walia, R. R., et al. (2017). Influenza A virus vaccines for swine. Vet. Microbiol. 206, 35-44. doi: 10.1016/j.vetmic.2016.11.026

Wang, D., Christopher, M. E., Nagata, L. P., Zabielski, M. A., Li, H., Wong, J. P., et al. (2004). Intranasal immunization with liposome-encapsulated plasmid DNA encoding influenza virus hemagglutinin elicits mucosal, cellular and humoral immune responses. J. Clin. Virol. 31, 99-106. doi: 10.1016/j.jcv.2004.09.013

Wang, W., Guo, Z., Chen, Y., Liu, T., and Jiang, L. (2006). Influence of generation 2-5 of PAMAM dendrimer on the inhibition of Tat peptide/TAR RNA binding in HIV-1 transcription. Chem. Biol. Drug Des. 68, 314-318. doi: 10.1111/ j.1747-0285.2006.00454.x

Wang, Y., Wang, X., Luo, G., and Dai, Y. (2008). Adsorption of bovin serum albumin (BSA) onto the magnetic chitosan nanoparticles prepared by a microemulsion system. Bioresource Technol. 99, 3881-3884. doi: 10.1016/ j.biortech.2007.08.017

Wang, J., Feng, S. S., Wang, S., and Chen, Z. Y. (2010). Evaluation of cationic nanoparticles of biodegradable copolymers as siRNA delivery system for hepatitis B treatment. Int. J. Pharm. 400, 194-200. doi: 10.1016/j.ijpharm. 2010.08 .026 
Wang, W., Wang, S.-X., and Guan, H.-S. (2012). The antiviral activities and mechanisms of marine polysaccharides: an overview. Marine Drugs 10, 27952816. doi: 10.3390/md10122795

Wang, H., Han, Q., Zhao, H., Xu, D., and Zhang, J. (2018). Single dose HBsAg CS$\gamma$-PGA nanogels induce potent protective immune responses against $\mathrm{HBV}$ infection. Eur. J. Pharm. Biopharm. 124, 82-88. doi: 10.1016/j.ejpb.2017.12.003

Wang, X., and Xing, B. (2007). Importance of structural makeup of biopolymers for organic contaminant sorption. Environ. Sci. Technol. 41, 3559-3565. doi: $10.1021 / \mathrm{es} 062589 \mathrm{t}$

Wedmore, I., McManus, J. G., Pusateri, A. E., and Holcomb, J. B. (2006). A special report on the chitosan-based hemostatic dressing: experience in current combat operations. J. Trauma Acute Care Surg. 60, 655-658. doi: 10.1097/ 01.ta.0000199392.91772.44

Wong, H. L., Chattopadhyay, N., Wu, X. Y., and Bendayan, R. (2010). Nanotechnology applications for improved delivery of antiretroviral drugs to the brain. Advanced Drug Delivery Rev. 62, 503-517. doi: 10.1016/ j.addr.2009.11.020

Wu, D., Ensinas, A., Verrier, B., Primard, C., Cuvillier, A., Champier, G., et al. (2016). Zinc-Stabilized Chitosan-Chondroitin Sulfate Nanocomplexes for HIV-1 Infection Inhibition Application. Mol. Pharm. 13, 3279-3291. doi: 10.1021/acs.molpharmaceut.6b00568

Xiao, B., Wan, Y., Zhao, M., Liu, Y., and Zhang, S. (2011). Preparation and characterization of antimicrobial chitosan- $\mathrm{N}$-arginine with different degrees of substitution. Carbohydr. Polymers 83, 144-150. doi: 10.1016/j.carbpol.2010.07.032

Yang, K. W., Li, X. R., Yang, Z. L., Li, P. Z., Wang, F., and Liu, Y. (2009). Novel polyion complex micelles for liver-targeted delivery of diammonium glycyrrhizinate: In vitro and in vivo characterization. J. Biomed. Mater. Res. Part A: Off. J. Soc. Biomater. Japanese Soc. Biomater. Aust. Soc. Biomater. Korean Soc. Biomater. 88, 140-148.

Yang, L., Chen, L., Zeng, R., Li, C., Qiao, R., Hu, L., et al. (2010). Synthesis, nanosizing and in vitro drug release of a novel anti-HIV polymeric prodrug: chitosan-O-isopropyl-5'-O-d4T monophosphate conjugate. Bioorg. Med. Chem. 18, 117-123. doi: 10.1016/j.bmc.2009.11.013

Yang, Y., Kuang, Y., Yuan, D., Cao, L. L., Wang, B. N., Li, M. Y., et al. (2011). [Investigation of HCV multi-epitope gene vaccine loaded by CTS-Fe3O4]. Sichuan Da Xue Xue Bao Yi Xue Ban 42, 757-61, 88.

Yang, J., Luo, K., Li, D., Yu, S., Cai, J., Chen, L., et al. (2013). Preparation, characterization and in vitro anticoagulant activity of highly sulfated chitosan. Int. J. Biol. Macromol. 52, 25-31. doi: 10.1016/j.ijbiomac.2012.09.027

Yang, Y., Liu, Y., Chen, S., Cheong, K.-L., and Teng, B. (2020a). Carboxymethyl $\beta$ cyclodextrin grafted carboxymethyl chitosan hydrogel-based microparticles for oral insulin delivery. Carbohydr. Polymers 246, 116617. doi: 10.1016/j.carbpol.2020.116617

Yang, Y., Xing, R., Liu, S., Qin, Y., Li, K., Yu, H., et al. (2020b). Chitosan, hydroxypropyltrimethyl ammonium chloride chitosan and sulfated chitosan nanoparticles as adjuvants for inactivated Newcastle disease vaccine. Carbohydr. Polym. 229, 115423. doi: 10.1016/j.carbpol.2019.115423

Yen, M.-T., Yang, J.-H., and Mau, J.-L. (2009). Physicochemical characterization of chitin and chitosan from crab shells. Carbohydr. Polymers 75, 15-21. doi: 10.1016/j.carbpol.2008.06.006

Yen, H.-L., McKimm-Breschkin, J. L., Choy, K.-T., Wong, D. D. Y., Cheung, P. P. H., Zhou, J., et al. (2013). Resistance to neuraminidase inhibitors conferred by an $\mathrm{R} 292 \mathrm{~K}$ mutation in a human influenza virus H7N9 isolate can be masked by a mixed R/K viral population. MBio 4. doi: 10.1128/mBio.00396-13

You, J., Hu, F.-Q., Du, Y.-Z., and Yuan, H. (2007). Polymeric micelles with glycolipid-like structure and multiple hydrophobic domains for mediating molecular target delivery of paclitaxel. Biomacromolecules 8, 2450-2456. doi: $10.1021 / \mathrm{bm} 070365 \mathrm{c}$

You, J., Hu, F.-Q., Du, Y.-Z., and Yuan, H. (2008). Improved cytotoxicity of doxorubicin by enhancing its nuclear delivery mediated via nanosized micelles. Nanotechnology 19, 255103. doi: 10.1088/0957-4484/19/25/255103

Yuki, Y., and Kiyono, H. (2003). New generation of mucosal adjuvants for the induction of protective immunity. Rev. Med. Virol. 13, 293-310. doi: 10.1002/rmv.398

Zeng, P., Xu, Y., Zeng, C., Ren, H., and Peng, M. (2011). Chitosan-modified poly (D,L-lactide-co-glycolide) nanospheres for plasmid DNA delivery and HBV gene-silencing. Int. J. Pharm. 415, 259-266. doi: 10.1016/j.ijpharm.2011.05.053
Zhai, Y., Zhou, Y., Li, X., and Feng, G. (2015). Immune-enhancing effect of nanoDNA vaccine encoding a gene of the prME protein of Japanese encephalitis virus and $\mathrm{BALB} / \mathrm{c}$ mouse granulocyte-macrophage colony-stimulating factor. Mol. Med. Rep. 12, 199-209. doi: 10.3892/mmr.2015.3419

Zhang, W., Yin, Z., Liu, N., Yang, T., Wang, J., Bu, Z., et al. (2010). DNA-chitosan nanoparticles improve DNA vaccine-elicited immunity against Newcastle disease virus through shuttling chicken interleukin-2 gene. J. Microencapsul 27, 693-702. doi: 10.3109/02652048.2010.507881

Zhang, N., Wardwell, P. R., and Bader, R. A. (2013). Polysaccharide-based micelles for drug delivery. Pharmaceutics 5, 329-352. doi: 10.3390/pharmaceutics5020329

Zhang, E., Xing, R., Liu, S., Qin, Y., Li, K., and Li, P. (2019). Advances in chitosanbased nanoparticles for oncotherapy. Carbohydr. Polymers 222, 115004. doi: 10.1016/j.carbpol.2019.115004

Zhao, L.-M., Shi, L.-E., Zhang, Z.-L., Chen, J.-M., Shi, D.-D., Yang, J., et al. (2011). Preparation and application of chitosan nanoparticles and nanofibers. Braz. J. Chem. Eng. 28, 353-362. doi: 10.1590/S0104-66322011000300001

Zhao, K., Zhang, Y., Zhang, X., Li, W., Shi, C., Guo, C., et al. (2014a). Preparation and efficacy of Newcastle disease virus DNA vaccine encapsulated in chitosan nanoparticles. Int. J. Nanomed. 9, 389-402. doi: 10.2147/IJN.S54226

Zhao, K., Zhang, Y., Zhang, X., Shi, C., Wang, X., Wang, X., et al. (2014b). Chitosan-coated poly(lactic-co-glycolic) acid nanoparticles as an efficient delivery system for Newcastle disease virus DNA vaccine. Int. J. Nanomed. 9, 4609-4619. doi: 10.2147/IJN.S70633

Zhao, K., Sun, Y., Chen, G., Rong, G., Kang, H., Jin, Z., et al. (2016). Biological evaluation of N-2-hydroxypropyl trimethyl ammonium chloride chitosan as a carrier for the delivery of live Newcastle disease vaccine. Carbohydr. Polym. 149, 28-39. doi: 10.1016/j.carbpol.2016.04.085

Zhao, K., Li, S., Li, W., Yu, L., Duan, X., Han, J., et al. (2017). Quaternized chitosan nanoparticles loaded with the combined attenuated live vaccine against Newcastle disease and infectious bronchitis elicit immune response in chicken after intranasal administration. Drug Delivery 24, 1574-1586. doi: 10.1080/10717544.2017.1388450

Zheng, M., Qu, D., Wang, H., Sun, Z., Liu, X., Chen, J., et al. (2016). Intranasal administration of chitosan against influenza A (H7N9) virus infection in a mouse model. Sci. Rep. 6, 28729. doi: 10.1038/srep28729

Zoulim, F., and Perrillo, R. (2008). Hepatitis B: reflections on the current approach to antiviral therapy. J. Hepatol. 48, S2-S19. doi: 10.1016/j.jhep.2008.01.011

Conflict of Interest: $\mathrm{MH}$ declares the following potential conflicts of interest. Scientific Advisory Boards: Transdermal Cap Inc, Cleveland, OH; BeWell Global Inc, Wan Chai, Hong Kong; Hologenix Inc. Santa Monica, CA; LumiTheraInc, Poulsbo, WA; Vielight, Toronto, Canada; Bright Photomedicine, Sao Paulo, Brazil; Quantum Dynamics LLC, Cambridge, MA; Global Photon Inc, Bee Cave, TX; Medical Coherence, Boston MA; NeuroThera, Newark DE; JOOVV Inc, Minneapolis-St. Paul MN; AIRx Medical, Pleasanton CA; FIR Industries, Inc. Ramsey, NJ; UVLRx Therapeutics, Oldsmar, FL; Ultralux UV Inc, Lansing MI; Illumiheal\&amp;Petthera, Shoreline, WA; MB Lasertherapy, Houston, TX; ARRC LED, San Clemente, CA; Varuna Biomedical Corp. Incline Village, NV; Niraxx Light Therapeutics, Inc, Boston, MA. Consulting; Lexington Int, Boca Raton, FL; USHIO Corp, Japan; Merck KGaA, Darmstadt, Germany; Philips Electronics Nederland B.V. Eindhoven, Netherlands; Johnson \&amp; Johnson Inc, Philadelphia, PA; Sanofi-Aventis Deutschland GmbH, Frankfurt am Main, Germany. Stockholdings: Global Photon Inc, Bee Cave, TX; Mitonix, Newark, DE.

The remaining authors declare that the research was conducted in the absence of any commercial or financial relationships that could be construed as a potential conflict of interest.

Copyright (c) 2021 Boroumand, Badie, Mazaheri, Seyedi, Nahand, Nejati, Baghi, Abbasi-Kolli, Badehnoosh, Ghandali, Hamblin and Mirzaei. This is an open-access article distributed under the terms of the Creative Commons Attribution License (CC BY). The use, distribution or reproduction in other forums is permitted, provided the original author(s) and the copyright owner(s) are credited and that the original publication in this journal is cited, in accordance with accepted academic practice. No use, distribution or reproduction is permitted which does not comply with these terms. 